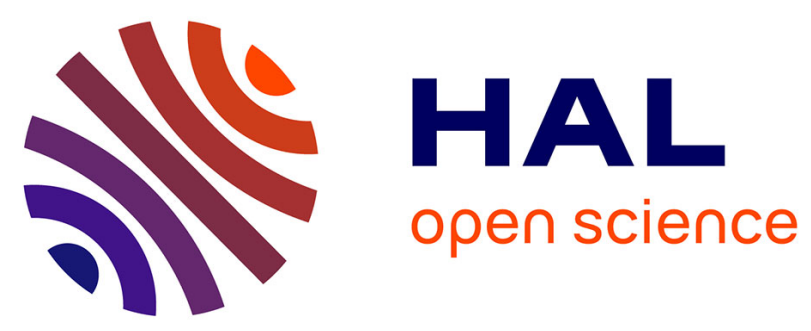

\title{
Comparative analysis of nanosystems' effects on human endothelial and monocytic cell functions.
}

\author{
Jasmin Matuszak, Philipp Dörfler, Stefan Lyer, Harald Unterweger, Maya \\ Juenet, Cédric Chauvierre, Amr Alaarg, Danielle Franke, Gunter Almer, \\ Isabelle Texier, et al.
}

\section{To cite this version:}

Jasmin Matuszak, Philipp Dörfler, Stefan Lyer, Harald Unterweger, Maya Juenet, et al.. Comparative analysis of nanosystems' effects on human endothelial and monocytic cell functions.. Nanotoxicology, 2018, 12 (9), pp.957-974. 10.1080/17435390.2018.1502375 . hal-02442441

\section{HAL Id: hal-02442441 \\ https://hal.science/hal-02442441}

Submitted on 16 Jan 2020

HAL is a multi-disciplinary open access archive for the deposit and dissemination of scientific research documents, whether they are published or not. The documents may come from teaching and research institutions in France or abroad, or from public or private research centers.
L'archive ouverte pluridisciplinaire $\mathbf{H A L}$, est destinée au dépôt et à la diffusion de documents scientifiques de niveau recherche, publiés ou non, émanant des établissements d'enseignement et de recherche français ou étrangers, des laboratoires publics ou privés. 


\section{Comparative analysis of nanosystems' effects on human endothelial and monocytic cell functions.}

Jasmin Matuszak $\ddagger^{1}$, Philipp Dörfler $\ddagger^{1}$, Stefan Lyer ${ }^{1}$, Harald Unterweger ${ }^{1}$, Maya Juenet ${ }^{2}$, Cédric Chauvierre ${ }^{2}$, Amr Alaarg ${ }^{3}$, Danielle Franke ${ }^{5}$, Gunter Almer ${ }^{6}$, Isabelle Texier ${ }^{7}$, Josbert M. Metselaar ${ }^{3,4}$, Ruth Prassl ${ }^{8}$, Christoph Alexiou ${ }^{1}$, Harald Mangge ${ }^{6}$, Didier Letourneur ${ }^{2}$, Iwona Cicha $^{1 *}$

${ }^{1}$ Section of Experimental Oncology and Nanomedicine (SEON), Else Kröner-FreseniusStiftung-endowed Professorship for Nanomedicine, ENT Department, University Hospital Erlangen, Friedrich-Alexander-Universität Erlangen-Nürnberg, Germany ${ }^{2}$ Inserm, U1148, LVTS, Paris Diderot University, X Bichat Hospital, Paris, France ${ }^{3}$ Department of Biomaterials Science and Technology, MIRA Institute for Biomedical Technology and Technical Medicine, University of Twente, Enschede,The Netherlands ${ }^{4}$ Department of Experimental Molecular Imaging, RWTH University Clinic Aachen, Germany ${ }^{5}$ nanoPET Pharma GmbH, Berlin, Germany

${ }^{6}$ Clinical Institute of Medical and Chemical Laboratory Diagnostics, Medical University of Graz, Graz, Austria

${ }^{7}$ Grenoble Alpes Université, Grenoble; CEA-LETI MINATEC Campus, Grenoble, France

${ }^{8}$ Institute of Biophysics, Medical University of Graz, Austria

$\ddagger$ Equally contributing authors

Running head: Effects of nanosystems on human endothelial and monocytic cells

Word count abstract: 237

Number of figures: 5

Number of tables: 1

Number of references: 55

* Corresponding author:

Iwona Cicha, $\mathrm{PhD}$

Cardiovascular Nanomedicine Unit

Section of Experimental Oncology and Nanomedicine

ENT Department, University Hospital Erlangen

Glückstr. 10a, 91054 Erlangen, Germany

Phone: +499131 8543953

Fax: +49 91318534282

E-mail: Iwona.Cicha@uk-erlangen.de 


\section{Abstract}

The objective of our work was to investigate the effects of different types of nanoparticles on endothelial (HUVEC) and monocytic cell functions. We prepared and tested 14 different nanosystems comprising liposomes, lipid nanoparticles, polymer and iron oxide nanoparticles. Some of the tested nanosystems contained targeting, therapeutic, or contrast agent(s). The effect of particles $(0-400 \mu \mathrm{g} / \mathrm{mL})$ on endothelial-monocytic cell interactions in response to TNF- $\alpha$ was investigated using an arterial bifurcation model and dynamic monocyte adhesion assay. Spontaneous HUVEC migration (0-100 $\mu \mathrm{g} / \mathrm{mL}$ nanoparticles) and chemotaxis of monocytic cells towards MCP-1 in presence of particles (0$400 \mu \mathrm{g} / \mathrm{mL}$ ) were determined using a barrier assay and a modified Boyden chamber assay, respectively. Lipid nanoparticles dose-dependently reduced monocytic cell chemotaxis and adhesion to activated HUVECs. Liposomal nanoparticles had little effect on cell migration, but one formulation induced monocytic cell recruitment by HUVECs under non-uniform shear stress by about 50\%. Fucoidan-coated polymer nanoparticles (25-50 $\mu \mathrm{g} / \mathrm{mL}$ ) inhibited HUVEC migration and monocytic cell chemotaxis, and had a suppressive effect on monocytic cell recruitment under non-uniform shear stress. No significant effects of iron oxide nanoparticles on monocytic cell recruitment were observed except lauric acid and human albumin-coated particles which increased endothelial-monocytic interactions by $60-70 \%$. Some of the iron oxide nanoparticles inhibited HUVEC migration and monocytic cell chemotaxis. These nanoparticle-induced effects are of importance for vascular cell biology and function and must be considered before the potential clinical use of some of the analyzed nanosystems in cardiovascular applications.

Keywords: nanoparticles, atherothrombosis, endothelial-monocyte interactions, endothelial migration, monocytic cell chemotaxis

\section{Introduction}


Nanotechnology is expected to improve the management and detection of atherothrombotic diseases (Mangge, et al., 2014), which constitute one of the biggest global health problems (Lozano, et al., 2012). By coating diagnostic nanosystems with plaque-specific ligands, significantly increased accumulation of these agents at the atherothrombotic sites could be achieved (Hamzah, et al., 2011), leading to improved detection and characterization of the disease. Furthermore, the direct targeting of drugdelivery nanosystems at the affected artery region could increase their therapeutic efficacy in parallel with reducing the systemic side effects. Vast numbers of bench investigations published in the recent produced very promising results (Cicha, et al., 2014, Bietenbeck, et al., 2016, Karimi, et al., 2016), but the clinical impact of nanoparticulate agents has been negligible in terms of diagnosis or therapy of cardiovascular diseases so far. The reasons for that are mainly the safety requirements, which are much higher for nanoparticulate cardiovascular drugs than for nanoparticulate cancer therapies. Consequently, the numbers of nanomedicines for cardiovascular applications entering the clinical trials are substantially smaller than in case of anti-cancer nanodrugs.

For the development of clinically safe nanoparticle-based systems for intravascular administration, systematic toxicological analyses of the candidate nanosystems are necessary. In our previous work, we performed standardized investigation of 10 nanoparticle types concerning their basic physicochemical parameters, long-term stability and the biocompatibility with endothelial cells (Matuszak, et al., 2016). The purpose of the present study was to provide new insights into the effects of different types of nanoparticles on human umbilical vein endothelial cell (HUVEC) and monocytic cell functions. Both endothelial and monocytic cell activation plays a major role in the development and progression of atherosclerosis. In endothelial cells, constantly exposed to the blood flow, the physiological functions greatly depend on shear stress-activated mechanisms. In fact, the susceptibility to atherosclerosis is governed by the specific patterns of shear stress. Whereas laminar flow protects endothelial cells from atherogenic stimuli, non-uniform shear stress induces endothelial activation and inflammatory cell recruitment (Cicha, et al., 2009). Increased monocyte chemotactic response and their migration into atherosclerotic lesions are the driving force in the disease progression. Hence, inhibition of leukocyte chemotaxis represents a target for an effective anti-atherosclerotic therapy. During all stages of atherosclerosis, endothelial injury contributes to atherothrombosis and increased accumulation of blood 
components in the vessel intima. The capacity of endothelial cells to proliferate and migrate is therefore crucial for endothelial regeneration and providing anti-thrombogenic barrier.

Thus far, very little is known about the influence of circulating nanoparticles on the endothelial responses to cytokines, monocyte chemotaxis, or endothelial-monocytic cell interactions. We have therefore investigated whether the presence of circulating nanosystems affects the TNF- $\alpha$-induced monocytic cell recruitment by endothelial cells grown under non-uniform shear stress conditions, and whether nanoparticles affect spontaneous endothelial cell migration and monocytic cells chemotaxis towards monocyte chemoattractant protein-1 (MCP-1). We analyzed diverse nanosystems, comprising liposomes, lipid nanoparticles, polymer and iron oxide nanoparticles. Some of the tested nanosystems contained a P-selectin targeting agent (fucoidan), a therapeutic substance (e.g. pravastatin, prednisolone), or a contrast agent (e.g. gadolinium chelate, iron oxide). In order to predict in vivo responses, we evaluated the effects of these nanosystems on primary HUVECs and a monocytic cell line, utilizing functional assays under conditions that resemble the physiological state.

\section{Materials \& methods}

\section{Reagents}

Soybean oil and Myrj ${ }^{\mathrm{TM}}$ s40 (PEGylated surfactant) were purchased from Croda, Chocques, France. Lipoid S75 and dipalmitoylphosphatidylcholine (DPPC) were from Lipoid GmbH, Ludwigshafen, Germany. SuppocireTM NB was from Gatefosse, Saint-Priest, France. 1-palmitoyl-2-oleoyl-sn-glycero3-phosphocholine (POPC), cholesterol, and 1,2-distearoyl-sn-glycero-3-phospho-ethanolamine-N[methoxy (polyethylene glycol)-2000] (DSPE-PEG-2000) were purchased from Avanti Polar Lipids, Inc. (Alabaster, AL, USA).

Dextran T70 was from Roth (Karlsruhe, Germany), or from Amersham Pharmacia Biotech (Freiburg, Germany), and dextran T40 from PharmaCosmos (Holbaek, Denmark). Carboxymethyl-dextran sodium salt (CM-Dextran) was purchased from Sigma Aldrich (Saint Quentin Fallavier, France) and diethylaminoethyl-dextran 20 (DEAE-dextran) from TdB Consultancy (Uppsala, Sweden). Low molecular weight Fucoidan (3-8 kDa, Ascophyscient ${ }^{\circledR}$ ) was from Algues et Mer (Ouessant, France). IBCA (isobutylcyanoacrylate, Glue 368) was from Orapi (Saint-Vulbas, France). Bovine serum albumin 
(BSA) and iron (II) chloride tetrahydrate, were from Merck, Darmstadt, Germany. Recombinant human serum albumin (HSA) was purchased from Novozymes Biopharma (Bagsvaerd, Denmark). Lauric acid, epichlorohydrin and dextran T40 (Mw, 40 kDa) were from Sigma Aldrich, Munich, Germany. Ceric (IV) ammonium nitrate and tri-sodium citrate dihydrate were purchased from Fluka (Saint Quentin Fallavier, France). $\mathrm{NaOH}, \mathrm{HCl}(25 \%), \mathrm{NH}_{3}(25 \%)$, and nitric acid (65\%w/w) were from Roth. Iron (III) chloride hexahydrate was purchased from Sigma-Aldrich or from Roth. Gadolinium chelate B22286 (DOTA-N-N-dioctadecylamide Gd(III)-complex) was kindly provided by Bracco (Milan, Italy). Pravastatin sodium was from AIkon Chemical (China/Brunschwig Chemie, The Netherlands) and prednisolone phosphate from BUFA (Uitgeest, The Netherlands). MCP-1 was purchased from Peprotech (Hamburg, Germany) and TNF- $\alpha$ from Miltenyi Biotec (Bergisch Gladbach, Germany). All compounds used were of pharmaceutical $(\mathrm{Ph}$. Eur) or highly pure ( $\geqslant 99 \%)$ grade and were used without any further purification.

Endothelial Cell Growth Medium with endothelial cell growth supplement was purchased from PromoCell (Heidelberg, Germany). RPMI 1640 medium, glutamine and fetal calf serum were from Biochrom AG, (Berlin, Germany), penicillin and streptomycin were from Gibco (Fisher Scientific, Schwerte, Germany) and Trypan blue from Biowest (Th.Geyer, Renningen, Germany). Alexa488phalloidin was from PromoKine (Heidelberg, Germany), nuclear stain DAPI from Molecular Probes (Darmstadt, Germany) and hematoxylin-eosin stain from Dako (Hamburg, Germany).

\section{Nanoparticle synthesis}

In total, 14 nanoparticle systems were investigated, including 5 types of liposomes (LP-NPs), 3 types of lipid nanoparticles (LD-NPs), 2 types of polymer nanoparticles (PM-NPs) and 4 types of iron oxide nanoparticles (IO-NPs). The detailed description of nanoparticle characterization methods was reported before (Matuszak, et al., 2016).

Liposomes: Liposomes are composed of a lipid bilayer that encloses an interior aqueous space (Puri, et al., 2009). The sterically stabilized PEGylated liposomes (LP-NP1), containing POPC, cholesterol and DSPE-PEG2000 at molar ratios of 3:2:0.15, were made using the lipid film hydration technique, 
followed by extrusion, as described previously (Almer, et al., 2011, Almer, et al., 2013). Gadoliniumloaded liposomes (Gd-LP-NP1) were prepared using the same method, with the following components: POPC:cholesterol:DSPE-PEG2000:B22286 at molar ratios of 3:2:0.15:0.78.

The LP-NP2 liposomes, containing DPPC, DSPE-PEG2000 and cholesterol (at 1.85: 0.15: $1 \mathrm{M}$ ratio), were prepared using the lipid injection method, by mixing the ethanolic lipid solution with the aqueous phase under magnetic stirring at $60^{\circ} \mathrm{C}$. The resulting coarse dispersion was downsized by multiple extrusion steps through polycarbonate filter membranes with decreasing pore sizes of (200-100 nm). Subsequently, ethanol and dissolved lipids were removed by dialysis against phosphate buffered saline (PBS). Pravastatin-loaded liposomes (Prava-LP-NP2) were alike synthesized by injection of solubilized lipids and pravastatin sodium ( $2 \mathrm{mg} / \mathrm{mL})$ into the aqueous phase. In order to remove ethanol, free drug and free lipids, the sample was dialysed by tangential flow filtration. Prednisolone-loaded liposomes (Predni-LP-NP2) were made by lipid injection into the aqueous solution containing $100 \mathrm{mg} / \mathrm{ml}$ prednisolone in water for injection (van der Geest, et al., 2015). Unencapsulated prednisolone was removed by dialysis against saline (molecular weight cut-off of $10 \mathrm{kDa}$ ).

Lipidots $^{\mathrm{TM}}$ : Lipid nanoparticles (LD-NPs) were prepared by the sonication method (Gravier, et al., 2011). Briefly, the lipid phase was prepared by mixing Suppocire ${ }^{\mathrm{TM}}$ NB, soybean oil and lipoid S75. The aqueous phase, containing Myrj ${ }^{\mathrm{TM}}$ s40 (PEGylated surfactant) in PBS, was heated to $50^{\circ} \mathrm{C}$ to melt the surfactant and then mixed with the lipid phase, followed by sonication and dialysis against PBS. The batches of particles with specified diameter were obtained by altering the lipid and surfactants ratios. Three different sizes (diameters) were formulated: $50 \mathrm{~nm}$ (LD-NP1), $80 \mathrm{~nm}$ (LD-NP2), and $120 \mathrm{~nm}$ (LD-NP3).

Polymer nanoparticles: PM-NPs were synthesized by a redox radical emulsion polymerization method (Chauvierre, et al., 2003). The core of the nanoparticles used in our studies (approximately $80 \%$ of the total mass) was made of poly(isobutylcyanoacrylate) (PIBCA), which was covalently cross-linked with polysaccharides of the coating, forming a hydrophilic shell. Two different coatings were used: (a) $90 \%$ CM-Dextran/10\% Fucoidan (FC-PM-NP1); and (b) 80\% DextranT70/10\% DEAE-dextran/10\% Fucoidan (FC-PM-NP2). Targeting ligand fucoidan, which is contained in the particle shell, is a mimic of sialyl Lewis X, the natural ligand of P-selectin (Bachelet, et al., 2009, Rouzet, et al., 2011). 
Iron oxide nanoparticles (IO-NP): Superparamagnetic iron oxide nanoparticles and ultrasmall superparamagnetic iron oxide nanoparticles (USPIOs) consist of an iron oxide core, which is coated with organic materials such as fatty acids, polysaccharides, or polymers. Four kinds of IO-NPs were used in the present study.

Lauric acid/BSA-coated magnetite nanoparticles (IO-NP1) were synthesized by coprecipitation under argon atmosphere, subsequent in situ coating with lauric acid, and formation of an artificial albumin corona as previously described (Zaloga, et al., 2014). Subsequently, IO-NP1 were purified by centrifugal ultrafiltration (molecular weight cut-off $100 \mathrm{kDa}$ ). IO-NP2 were prepared according to the same protocol, whereby BSA was replaced with clinically-approved HSA formulation. IO-NP3 nanoparticles were synthesized by the coprecipitation method under nitrogen atmosphere, followed by coating with carboxydextran as described previously (Matuszak, et al., 2016). For preparation of dextran-coated USPIOs (IO-NP4), the synthesis method developed by Unterweger et al. was used (Unterweger, et al., 2014). Particles were synthesized by coprecipitation under argon atmosphere, in the presence of dextran T40. To stabilize the dextran coating, crosslinking was performed using epichlorohydrine (Unterweger, et al., 2017).

All particles used in this study were stored at $4^{\circ} \mathrm{C}$ and, prior to their use in cell culture experiments, sterilized by filtration through a $0.22 \mu \mathrm{m}$ filter, with the exception of PM-NPs, for which $0.45 \mu \mathrm{m}$ filters were used. This was due to the fact that the average hydrodynamic diameter of FC-PM-NP2 is around $227 \mathrm{~nm}$, i.e. the same size as the pores of the $0.22 \mu \mathrm{m}$ filters, which inevitably results in rapid clogging. To be in accordance with the further in vitro tests, we also used the $0.45 \mu \mathrm{m}$ filter for FC-PM-NP1, despite the fact that their size allowed filtration through a $0.22 \mu \mathrm{m}$ filter.

\section{Physicochemical characterization}

Z-averaged hydrodynamic diameter, polydispersity (PDI) and $\zeta$-potential were determined in water with a Zetasizer Nano ZS (Malvern). The detailed description of further characterization methods relevant for the respective nanoparticle types was reported previously (Matuszak, et al., 2016). The composition and basic characteristics of all tested nanosystems used in the present study are summarized in Table 1 . 


\section{Cell culture and viability assays}

Human umbilical vein endothelial cells (HUVECs) were isolated from freshly collected umbilical cords (kindly provided by the Dept. of Gynaecology, Prof. Beckmann, University Hospital Erlangen) (Cicha, et al., 2009). The use of human material was approved by the local ethics committee at the University Hospital Erlangen (review number 237_12B from 19.09.2012). Cells were cultured in Endothelial Cell Growth Medium with endothelial cell growth supplement containing 5\% fetal calf serum, $4 \mu \mathrm{L} / \mathrm{mL}$ heparin, $10 \mathrm{ng} / \mathrm{mL}$ epidermal growth factor and $1 \mu \mathrm{g} / \mathrm{mL}$ hydrocortisone, at humidified $5 \% \mathrm{CO}_{2}$ atmosphere. HUVECs at passage 1-2 were used. Prior to the functional assays, all tested nanosystems underwent the analysis of biocompatibility with HUVECs using real-time cell analysis and live-cell microscopy in static conditions, as well as the evaluation of potential cytotoxicity under arterial flow conditions, according to established methods (Matuszak, et al., 2016). Real-time cell analysis was used to estimate cell number, attachment and viability based on the impedance measurements, but did not allow the detailed observations on cell morphology. Therefore, live-cell microscopy was used as a complementary method to monitor HUVEC phenotype and confluence over incubation time.

THP-1 monocytic cells were cultured in RPMI 1640 medium supplemented with 2 mmol/L glutamine, $100 \mathrm{U} / \mathrm{mL}$ penicillin, $100 \mu \mathrm{g} / \mathrm{mL}$ streptomycin and $10 \%$ fetal calf serum. Viability of cells was greater than $98 \%$ as estimated by Trypan blue exclusion.

\section{HUVEC confluence under flow conditions}

The bifurcating flow-through cell culture slides were obtained from Ibidi ${ }^{\circledR}$ (Munich, Germany). Numerical flow simulation (Cicha, et al., 2009) distinguished the region of laminar shear stress (10.210.8 dyne $/ \mathrm{cm}^{2}$ at a flow rate of $9.6 \mathrm{~mL} / \mathrm{min}$ ) throughout the straight main channel, and the region of non-uniform shear stress at the outer walls of bifurcation (shear stress range from $\sim 6.3 \mathrm{dyne} / \mathrm{cm}^{2}$ to $\sim 0.5$ dyne $/ \mathrm{cm}^{2}$ ). HUVECs at $7 \times 10^{5} / \mathrm{mL}$ were seeded in the bifurcating slides and grown until confluence. Using a programmed peristaltic pump (Ismatec, Wertheim, Germany), the cell monolayer inside the slide channel was perfused with medium (with or without nanoparticles) at arterial shear stress for $18 \mathrm{~h}$. For the perfusion with nanoparticles, 2 different concentrations were used $(100 \mu \mathrm{g} / \mathrm{mL}$ and $400 \mu \mathrm{g} / \mathrm{mL})$. Concentrations for iron oxide nanoparticles were calculated as total iron (Fe) concentration. The 
concentrations for lipid nanoparticles, liposomes and polymeric nanoparticles were calculated as total dry mass weight per volume. After $18 \mathrm{~h}$, slides were detached from the pump system, washed with PBS and fixed with $4 \%$ formalin for 10 min at RT. HUVECs were stained with Alexa488-phalloidin. Cell nuclei were counterstained with DAPI. Images were obtained using fluorescence microscope Zeiss Axio Observer.Z1 (Carl Zeiss AG, Oberkochen, Germany). The confluence was determined on x20 objective magnification images using ImageJ software.

\section{Dynamic monocyte adhesion assay}

HUVECs were exposed to flow in the presence of circulating nanoparticles for $18 \mathrm{~h}$, as described above. Afterwards, HUVECs were stimulated with $2.5 \mathrm{ng} / \mathrm{mL}$ TNF- $\alpha$ for $2 \mathrm{~h}$, followed by perfusion for $1 \mathrm{~h}$ with fresh endothelial cell medium containing THP-1 monocytic cells $\left(7 \times 10^{5}\right.$ cells $\left./ \mathrm{mL}\right)$ at the same flow rate (Cicha, et al., 2009). Non-adherent cells were removed by stringent washing. Following the fixation with $4 \%$ paraformaldehyde, adherent monocytic cells were visualized using hematoxylin-eosin stain and digitally counted in minimum 8 image fields $\left(0.89 \mathrm{~mm}^{2}\right)$ at x100 magnification in non-uniform shear stress area. The mean number of nanoparticle-untreated adherent monocytic cells in non-uniform shear stress region was set as $100 \%$.

\section{Endothelial cell migration assay}

HUVEC migration was assessed in a modified barrier assay using silicone cell culture inserts from Ibidi (Munich, Germany). HUVECs were seeded in 2 wells separated by a $500 \mu \mathrm{m}$ insert barrier, at a concentration of $3 \times 10^{5} / \mathrm{mL}$. The cells were pre-treated with 0,50 or $100 \mu \mathrm{g} / \mathrm{mL}$ nanoparticles overnight. Afterwards, the inserts were carefully removed, creating a $500 \mu \mathrm{m}$-wide gap between the two cell monolayers. HUVECs were washed then and further incubated with medium containing the appropriate concentrations of nanoparticles for additional $24 \mathrm{~h}$, during which the closing of the gap created by insert removal was monitored. The gap size between the 2 monolayers was recorded at the insert removal point (0 h), at 12 and 24 hours using an Incucyte FLR system. Cell-free areas at different time points were measured using ImageJ software. The effect of nanoparticles on cell migration was assessed by 
calculating the increase in the area occupied by cells at later time points compared with the cell-covered area at $0 \mathrm{~h}$.

\section{Chemotaxis assay}

The effect of nanosystems on monocytic cell migration was assessed in a 96-well Chemo-Tx plate (NeuroProbe, Gaithersburg, MD, USA). THP-1 monocytic cells were incubated with 0, 12.5, 25, 50, 100, 200 or $400 \mu \mathrm{g} / \mathrm{mL}$ particles for $2 \mathrm{~h}$ at $37^{\circ} \mathrm{C}$ and under constant stirring. Briefly, the microplate wells were filled with $30 \mu \mathrm{L}$ serum-free RPMI 1640 . MCP-1 (50 ng/mL) was used as a positive control. After placing the filter frame, the filter top sites with $5 \mu$ m-pores were filled with $25 \mu \mathrm{L}$ of nanoparticletreated monocytic cells at a concentration of $1 \times 10^{6}$ cells $/ \mathrm{mL}$. Following incubation for $1 \mathrm{~h}$ at $37^{\circ} \mathrm{C}$, migrated non-adherent cells from the lower wells were fixed and counted using flow cytometry. All samples were run in quadriplicate and averaged. The mean number of migrated cells in the positive control (MCP-1 stimulated) samples was set as $100 \%$.

\section{Statistical analyses}

The comparison between untreated and nanoparticle-treated samples was done using Student's T-test, for samples with normal distribution (according to Shapiro-Wilk test). Signed Rank test, Mann-Whitney test, or Kruskal-Wallis test (ANOVA on ranks) was used for the samples with non-parametric distribution. The multiple comparisons were performed with Tukey test. The analysis was done using SigmaStat/SigmaPlot statistical software. Data were expressed as mean \pm SEM, unless stated otherwise. $\mathrm{P}<0.05$ was considered statistically significant.

\section{Results}




\section{Nanoparticle characterisation and long-term effects on endothelial viability}

The detailed description of physicochemical properties of respective nanoparticles was previously reported elsewhere (Matuszak, et al., 2016, Almer, et al., 2011, Almer, et al., 2013, Gravier, et al., 2011, Zaloga, et al., 2014, Unterweger, et al., 2014). Prior to the functional assays, all tested nanosystems underwent the analysis of biocompatibility with HUVECs. Figure 1 shows the heat-map summarizing the effects of diverse nanosystems on HUVEC viability, measured by real-time cell analysis and livecell microscopy, and on their confluence under flow conditions. The corresponding graphs showing the effect of each type of nanoparticles on HUVEC viability at $24 \mathrm{~h}$ and example images are presented in Supplementary Fig. 1-7.

\section{Nanoparticle effects on monocytic cell recruitment by HUVECs}

Lining the lumen of the entire vascular tree, endothelial cells are constantly exposed to the blood flow, the patterns of which determine their responses to stimuli. Whereas laminar flow protects endothelial cells from harmful stimuli, non-uniform shear stress induces endothelial activation (Cicha, et al., 2009), and contributes to atherosclerotic plaque development. To investigate the effect of nanosystems on the endothelial-monocytic cell interactions in response to inflammatory stimulus and non-uniform shear stress, HUVECs were perfused with medium containing 100 or $400 \mu \mathrm{g} / \mathrm{mL}$ of nanoparticles for $18 \mathrm{~h}$. Subsequently, the cells were treated with TNF- $\alpha$ for $2 \mathrm{~h}$, followed by the dynamic adhesion assay.

\section{Liposomes}

The experiments with LP-NP1 and Gd-LP-NPs showed a significant reduction in monocytic cell adhesion to activated endothelium both at 100 and $400 \mu \mathrm{g} / \mathrm{mL}$ (Fig. 2A, Supplementary Fig. 8A). In contrast, the treatment with LP-NP2 resulted in a dose-dependent increase in the monocytic cell recruitment under non-uniform shear stress. This effect was statistically significant at both 100 and 400 $\mu \mathrm{g} / \mathrm{mL}$, reaching about 30\% increase at $400 \mu \mathrm{g} / \mathrm{mL}$ (Fig. 2 B). In samples treated with $100 \mu \mathrm{g} / \mathrm{mL}$ of pravastatin-loaded liposomes (Prava-LP-NP2), a 20\% decrease in monocytic cell recruitment occurred, which was not observed in samples treated with $400 \mu \mathrm{g} / \mathrm{mL}$. Compared to untreated samples, PredniLP-NP2 had no effect on monocytic cell recruitment. 


\section{Lipid nanoparticles}

Because lipid nanoparticles at $200 \mu \mathrm{g} / \mathrm{mL}$ and above induced alterations in endothelial morphology (see also Supplementary Fig. 9; (Matuszak, et al., 2016)), reduced LD-NP concentrations have been applied in the present experiments (50 and $100 \mu \mathrm{g} / \mathrm{mL}$ LD-NPs instead of 100 and $400 \mu \mathrm{g} / \mathrm{mL}$ ). Independent of their size, all LD-NPs caused a reduction in monocytic cell recruitment by activated HUVECs, with a strongest, dose-dependent effect observed in cells treated with LD-NP1 (50 nm) (Fig. 2C). In samples treated with LD-NP3 $(120 \mathrm{~nm})$, a similar reduction was observed. LD-NP2 (80 nm) had somewhat weaker inhibiting effect on monocytic cell recruitment as compared to untreated controls (Fig. 2C).

\section{Polymer nanoparticles}

Because of endothelial toxicity observed at $100 \mu \mathrm{g} / \mathrm{mL}$ of polymer particles under flow conditions in our previous studies (see also Supplementary Fig. 5 and Suppl. Fig. 10; (Matuszak, et al., 2016)), reduced nanoparticle concentrations have been applied in the present experiments (25 and $50 \mu \mathrm{g} / \mathrm{mL}$ FC-PM-NPs instead of 100 and $400 \mu \mathrm{g} / \mathrm{mL}$ ). FC-PM-NP1 caused a strong 40-45\% reduction in the number of recruited monocytic cells, which was statistically significant at both 25 and $50 \mu \mathrm{g} / \mathrm{mL}$ (Fig. 2D). Similar effect, and about $40 \%$ reduction in monocytic cell recruitment was observed in HUVECs exposed to 25 and $50 \mu \mathrm{g} / \mathrm{mL}$ FC-PM-NP2 (Fig. 2D, Supplementary Fig. 8B).

\section{Iron oxide nanoparticles}

Among iron oxide nanoparticles, no major effect of the treatment with IO-NP1, IO-NP3 or IO-NP4 on monocytic cell recruitment under non-uniform shear stress was detectable. Solely at $100 \mu \mathrm{g} / \mathrm{mL}$ IONP3, a slight reduction in the numbers of recruited monocytic cells was observed, but it was not detectable at the higher particle concentration. In HUVECs treated with IO-NP2, a significant increase in the numbers of adherent monocytic cells under non-uniform shear stress was detected at 100 and 400 $\mu \mathrm{g} / \mathrm{mL}$ (Fig. 2E).

\section{Nanoparticle effects on endothelial cell migration}

The effect of nanosystems on spontaneous endothelial cell migration was assessed utilizing a modified wound-closing assay.

Liposomes 
No effect of HUVEC incubation with LP-NP1 or Gd-LP-NP1 was observable. The analyses of the blank LP-NP2, Prava-LP-NP2 and Predni-LP-NP2 also showed no major effect of these particles on the spontaneous endothelial cell migration at 12 or $24 \mathrm{~h}$ (not shown).

\section{Lipid nanoparticles}

Independent of size, none of LD-NPs affected endothelial cell migration at $24 \mathrm{~h}$. In the HUVEC samples treated with the smallest lipidots (LD-NP1), a transient reduction in gap-closure speed was detected at $12 \mathrm{~h}$ post-insert removal, but it was no longer observable after $24 \mathrm{~h}$ of migration (Fig. 3A).

\section{Polymer nanoparticles}

Treatment of HUVECs with FC-PM-NP1 resulted in a slight inhibition of migration, whereby at $24 \mathrm{~h}$ after the barrier removal, $75 \%$ of the gap was closed both at 50 and $100 \mu \mathrm{g} / \mathrm{mL}$, as compared with $100 \%$ in untreated samples (Fig. 3B). In samples treated with FC-PM-NP2, very strong inhibition of migration was observed: At $24 \mathrm{~h}$, only $50 \%$ of the gap was closed at nanoparticle concentration of $50 \mu \mathrm{g} / \mathrm{mL}$, and only $20 \%$ at $100 \mu \mathrm{g} / \mathrm{mL}$. This corresponded to $80 \%$ reduction in migration speed as compared to untreated controls (Fig. 3B, Supplementary Fig. 11).

\section{Iron oxide nanoparticles}

In HUVECs treated with IO-NP1, no effect on endothelial cell migration was observed at $12 \mathrm{~h}$. After 24 h, inhibition of migration by about 35\% at both tested concentrations was detected, as compared to untreated control (Fig. 3C). In the HUVEC samples treated with $100 \mu \mathrm{g} / \mathrm{mL}$ IO-NP2, a transient, significant reduction in gap-closure speed was detected at $12 \mathrm{~h}$ post-insert removal, but it was no longer observable after $24 \mathrm{~h}$ of migration.

Treatment with IO-NP3 more strongly affected endothelial cell migration: At $100 \mu \mathrm{g} / \mathrm{mL}$ IO-NP3, only $20 \%$ of the original gap was closed after $12 \mathrm{~h}$, compared to nearly $60 \%$ in control. After $24 \mathrm{~h}$ of migration, untreated control samples showed a complete closure of the gap, whereas only $40 \%$ of the gap was covered by cells treated with $100 \mu \mathrm{g} / \mathrm{mL}$ IO-NP3 (Fig. 3C, Supplementary Fig. 11). Dextrancoated USPIO (IO-NP4) had no effect on spontaneous endothelial migration (not shown).

\section{Nanoparticle effects on THP-1 monocytic cell chemotaxis}


Monocyte chemotaxis and migration into the vessel wall are the driving force in atherosclerosis. We have therefore investigated the effects of the nanosystems on chemotactic response of THP-1 monocytic cells to MCP-1.

\section{Liposomes}

Upon 2 h-incubation of monocytic cells with LP-NP1, a dose-dependent reduction in transmigrated cell numbers was observed, reaching about $50 \%$ of positive control at $200 \mu \mathrm{g} / \mathrm{mL}$. In contrast, this effect was abolished upon treatment of monocytic cells with Gd-LP-NP1 (Fig. 4A).

A different effect was observed for LP-NP2, which in their basic form had no effect on monocytic cell chemotaxis. Pravastatin-loaded liposomes (Prava-LP-NP2) caused a strong dose-dependent reduction in chemotaxis, whereby at $100 \mu \mathrm{g} / \mathrm{mL}$, the numbers of transmigrated monocytic cells were decreased to $50 \%$ of positive control (nanoparticle-untreated). Interestingly, this decrease was not detectable in monocytic cells treated with Predni-LP-NP2 (Fig. 4B).

\section{Lipid nanoparticles}

Independent of their size, all LD-NPs caused a dose-dependent decrease in monocytic cell chemotaxis. This reduction was strongest for LD-NP2 and LD-NP3, with about 70\% reduction relative of nanoparticle-untreated positive control observed at $100 \mu \mathrm{g} / \mathrm{mL}$ (Fig. 4C).

\section{Polymer nanoparticles}

Both types of FC-PM-NPs resulted in a very strong dose-dependent inhibition of monocytic cell chemotaxis (Fig. 5A). At $200 \mu \mathrm{g} / \mathrm{mL}$, the numbers of transmigrated monocytic cells were reduced down to negative control levels (without MCP-1).

\section{Iron oxide nanoparticles}

In THP-1 samples treated with different concentrations of IO-NP1, a biphasic effect on monocytic cell chemotaxis was observed. Between 12.5-100 $\mu \mathrm{g} / \mathrm{mL}$, a decrease by 30\% in numbers of transmigrated monocytic cells was detected, whereas at $200 \mu \mathrm{g} / \mathrm{mL}$ the numbers similar to positive control levels and at $400 \mu \mathrm{g} / \mathrm{mL} \mathrm{50 \%} \mathrm{increase} \mathrm{in} \mathrm{migrated} \mathrm{monocytic} \mathrm{cells} \mathrm{was} \mathrm{noted} \mathrm{(Fig.} \mathrm{5B).} \mathrm{In} \mathrm{samples} \mathrm{treated} \mathrm{with}$ IO-NP2 and IO-NP3, a similar but less pronounced effect was observed. At $50 \mu \mathrm{g} / \mathrm{mL}$ of IO-NP2 and $25 \mu \mathrm{g} / \mathrm{mL}$ IO-NP3, the numbers of transmigrated monocytic cells were decreased by $20 \%$. A slight increase in monocytic chemotaxis was detected at $200 \mu \mathrm{g} / \mathrm{mL}$ of IO-NP2, and the number of migrated monocytic cells dramatically increased at $400 \mu \mathrm{g} / \mathrm{mL}$ (Fig. 5B). Slight increase in monocytic cell 
chemotaxis was also observed at $400 \mu \mathrm{g} / \mathrm{mL}$ IO-NP3. IO-NP4 had no effect on monocytic cell chemotaxis (Fig. 5C).

Within $2 \mathrm{~h}$ of incubation, no effect of nanoparticle treatment on THP-1 monocytic cell viability, as determined by flow cytometry, was detected (not shown).

\section{Discussion}

The concept of nanomedicine encompasses a localized delivery of nanosystems to the diseased tissues and minimized systemic side effects. However, an extended circulation time of nano-sized particles compared to free drugs may result in enhanced particle interactions with vascular and blood cells, potentially contributing to cytotoxicity (Kumar, et al., 2013), or immunogenicity (Zolnik, et al., 2010). In this context, studies in cell culture models under physiological-like conditions represent a useful tool to predict nanoparticle behaviour in vivo (Desai, 2012), including their cellular uptake and the effects on cell functions. Here, we investigated 14 nanoparticle systems, comprising lipid nanoparticles (Lipidots ${ }^{\mathrm{TM}}$ ), liposomes, polymeric nanoparticles, and iron oxide nanoparticles with regard to their functional effects on atherosclerosis-relevant cells. Our previous studies indicated that nanoparticle sedimentation in static conditions may increase their effective concentrations in the vicinity of cell monolayer, contributing to an enhanced cytotoxicity over time (Matuszak, et al., 2016). Although in vivo, doses above $100 \mu \mathrm{g} / \mathrm{mL}$ are not expected to occur systemically, they may be encountered locally at the vascular regions of bolus administration. We have therefore tested nanoparticle effects in the dynamic assays up to a concentration of $400 \mu \mathrm{g} / \mathrm{mL}$, and correspondingly reduced the maximal nanoparticle concentrations in the HUVEC migration assay, which is performed in static conditions over prolonged period of time. As some of the nanosystems are expected to remain in circulation for several hours or more, we selected long-term monitoring for the investigations involving HUVECs. Short-term exposure was solely used in THP-1 monocytic cells ( $2 \mathrm{~h}$ incubation) to investigate the effect of nanosystems on chemotaxis. It must be therefore noted that more pronounced effects are possible upon prolonged exposure of these cells to nanoparticles. The diverse tested nanosystems and their utility for cardiovascular applications in the light of the obtained results are briefly discussed below. 


\section{Lipid-based nanoparticles}

Apart from the ease of preparation, the advantages of lipid nanoparticles and liposomes as imaging or drug-delivery platforms also include their reported low immunogenicity (Huwyler, et al., 2008, Muller, et al., 2011), which is expected to enable safe and repeated administration. Liposomes, which are composed of a lipid bilayer that encloses an interior aqueous space (Puri, et al., 2009), are commonly functionalized with polymerizable moieties to improve stability (e.g. PEGylated stealth liposomes). Concerning the endothelial compatibility, all liposome types tested in this study showed superb properties, with little or no effect on HUVEC viability or morphology up to $400 \mu \mathrm{g} / \mathrm{mL}$. None of the formulations affected the migratory capacities of HUVECs. However, we observed other functional effects on HUVECs and monocytic cells, which were dependent on the type of liposomal formulation and/or the type of the loaded compound. Treatment with either empty or Gd-loaded LP-NP1 reduced monocytic cell recruitment by HUVECs grown under non-uniform shear stress conditions. Interestingly, whereas LP-NP1 dose-dependently reduced monocytic cell chemotaxis towards MCP-1, this effect was abolished in cells treated with Gd chelate-loaded liposomal particles. Both linear and macrocyclic Gd chelates have been previously shown to induce a proinflammatory phenotype in human monocytes in vitro (Wermuth, et al., 2014). Our present findings may thus indicate that the presence of chelator influences the cellular interactions and functional effects of liposomes on monocytic cells.

In case of LP-NP2 synthesized by lipid phase injection, non-uniform shear stress and TNF- $\alpha$-induced recruitment of monocytic cells by HUVECs was significantly increased. This unexpected proinflammatory effect of basic LP-NP2 liposomes was drastically reduced by the presence of either pravastatin or prednisolone. Both these drugs belong to the classes of pharmaceutics known for their anti-inflammatory properties and were previously reported to reduce monocytic cell adhesion to endothelium (Pozo, et al., 2006, Gelati, et al., 1997, Simoncini, et al., 2000). Regarding monocytic cell chemotaxis, no effect of LP-NP2 was observed, except in cells treated with Prava-LP-NP2, which induced a strong dose-dependent decrease in chemotaxis. These findings were consistent with the previously reported interference of another nanoparticle-bound statin (pitavastatin) with MCP-1/CCR2 signaling (Katsuki, et al., 2014), underscoring the anti-inflammatory and anti-atherogenic potential of this class of drugs (Wong, et al., 2001). 
Lipid nanoparticles used in this study (Lipidots ${ }^{\mathrm{TM}}$ ) display increased affinity for myeloid cells such as macrophages, or denditric cells (Courant, et al., 2017), and a biodistribution pattern with high uptake in lipid-rich areas, such as adrenals, ovaries and testis, and liver, where they are metabolized (Merian, et al., 2013). Their size is easily adjustable and lipid composition is similar to those of low density lipoproteins. Although Lipidots ${ }^{\mathrm{TM}}$ do not present apolipoprotein on their surface, it is highly probable that apolipoproteins efficiently bind to the LD-NP surface once in blood, as previously reported for similar lipid nanoparticles (Goppert, et al., 2005, Goppert, et al., 2005). Because of these features, LDNPs are considered highly interesting nanosystems for atherosclerotic plaque targeting. Similar to liposomes, lipid nanoparticles used in this study had an overall good biocompatibility with HUVECs, whereby some effect on endothelial morphology and viability were previously observed at and above $200 \mu \mathrm{g} / \mathrm{mL}$ (Matuszak, et al., 2016). Independent of their size, LD-NPs had little effect on spontaneous HUVEC migration, but strongly and dose-dependently prevented monocytic cell chemotaxis. Since no effect of LD-NPs on monocytic cell viability during $2 \mathrm{~h}$ incubation was detectable, the effect was likely mediated at a CCR2 receptor level. All LD-NPs tested in the present study also strongly reduced endothelial recruitment of monocytic cell adhesion. Overall, these results indicate that empty LD-NPs possess certain anti-inflammatory potential, which could potentially be enhanced by appropriate drug payload.

\section{Polymer nanoparticles}

Synthetic and natural polymers have been previously used in the design of nanostructures for the treatment and diagnosis of cardiovascular diseases (Mura, et al., 2012). Their advantage is the presence of tunable surface properties that enable easy grafting of functional groups. In this work, redox radical emulsion polymerization of isobutylcyanoacrylate monomers was used to produce nanoparticles with a hydrophobic PIBCA core covered with a brush-like shell composed of dextran and fucoidan (Chauvierre, et al., 2003). PIBCA polymer has been chosen for its biodegradability and biocompatibility (Muller, et al., 1990). For colloidal stability and biocompatibility (Berry, et al., 2003), dextrans, stable glucose polymers that contain functional groups for derivatization (Sun, et al., 2012), were used. Both types of PM-NPs were functionalized with $10 \%$ fucoidan, a negatively charged polysaccharide that contains high percentages of L-fucose and sulphate ester groups. Fucoidan, a mimic of sialyl Lewis X, 
the natural ligand of P-selectin expressed by activated endothelial cells and platelets (Bachelet, et al., 2009, Rouzet, et al., 2011), is of great interest for the treatment and diagnosis of atherothrombosis, e.g to detect intraluminal thrombi or activated endothelium in atherosclerotic lesions (Porter, 2007, Libby, et al., 2010).

Concerning the functional effects of FC-PM-NPs observed in our study, both particle types strongly prevented monocytic cell recruitment by HUVECs exposed to non-uniform shear stress and TNF- $\alpha$, independent of their dose within this setup. Moreover, a strong and dose-dependent reduction of monocytic cell chemotaxis towards MCP-1 was observed. These effects are likely to result from competitive receptor binding of fucoidan to selectins on HUVECs and their ligands on monocytic cells, which prevents subsequent ligand-receptor interactions (Polley, et al., 1991, Heinzelmann, et al., 1998, Zandberg, et al., 2012, Cumashi, et al., 2007), thus contributing to anti-inflammatory effects. At the tested concentrations, no effects of FC-PM-NPs on cell viability were observed.

Concerning endothelial migration, strong to very strong dose-dependent inhibition in spontaneous gap closing was detected in samples treated with polymer nanoparticles. This effect was more pronounced in HUVECs treated with FC-PM-NP2, which at $100 \mu \mathrm{g} / \mathrm{mL}$ nearly prevented the migration of HUVECs. At the same time, the viability of cells was not affected, indicating that the mechanism of this phenomenon was likely related to the particle interference with actin cytoskeleton regulation, which is necessary for cell motility. The strong differences observed between the two types of FC-PM-NPs may be related to their different sizes and surface charges: Zeta potential values (Table 1) indicate that the surface charge was greatly influenced by the charge of the shell polysaccharides [11], whereby CMdextran and fucoidan contained in FC-PM-NP1 shell are negatively charged. These polysaccharide chains are also shorter, which results is smaller particle size. On the contrary, DEAE-dextran is positively charged and dextran is neutral, resulting in a slightly positive charge of FC-PM-NP2, which together with their larger size may contribute to an increased internalization by HUVECs and enhancement of the elicited effects.

Iron oxide nanoparticles 
SPION and USPIO have strong contrast-enhancing properties in magnetic resonance imaging (MRI), enabling plaque detection and characterization (Trivedi, et al., 2006, Howarth, et al., 2009, Tang, et al., 2009, Sadat, et al., 2013), as well as cell-tracking in vivo (Richards, et al., 2012). Furthermore, the magnetic properties of these particles allow their remote targeting by means of external magnetic field (Janko, et al., 2013, Lyer, et al., 2010, Tietze, et al., 2013), as well as their application for hyperthermiatherapy. IO-NPs have overall good biocompatibility when stabilized with coating, and the formulations used here were well tolerated by ECs as shown in our former (Matuszak, et al., 2016) and present studies. Compared to all other IO-based nanosystems tested, dextran-coated USPIO (IO-NP4) were most bioinert and did not elicit any functional effects on EC migration, monocytic cell chemotaxis or endothelial-monocytic interactions under flow conditions. The reason for this is likely related to the very low internalization of IO-NPs coated with crosslinked dextran by non-phagocytic cells, as previously shown for larger particles of this type (Unterweger, et al., 2017).

Among the tested IO-NPs with fatty acid-coating, LA/ BSA-coated IO-NP1 did not significantly affect monocytic cell recruitment by activated ECs. In contrast, upon prolonged incubation, they induced an inhibitory effect on HUVEC migration. Moreover, a biphasic effect was observed in monocytic cell samples treated with IO-NP1, whereby between 12.5 and $100 \mu \mathrm{g} / \mathrm{mL}$, chemotaxis was significantly reduced independent of the dose and returned to control levels at $200 \mu \mathrm{g} / \mathrm{mL}$, followed by further nonsignificant increase above this concentration. In contrast to IO-NP1, IO-NP2 particles coated with LA and HSA induced a massive enhancement of the pro-inflammatory response in HUVECs. The reason for this strong effect is unknown. Physiological concentrations of BSA have been previously shown to inhibit TNF- $\alpha$ induced VCAM-1 expression in HUVECs (Zhang, et al., 2002), whereas glycated BSA had opposite effect (Desfaits, et al., 1999). It is therefore unclear what pro-inflammatory mechanism is induced or enhanced by HSA-coated particles in HUVECs exposed to atherogenic shear stress. At the same time, IO-NP2 did not affect endothelial migration and had no significant effect on monocytic cell chemotaxis up to $200 \mu \mathrm{g} F / \mathrm{mL}$. Solely at the highest tested concentration (400 $\mu \mathrm{g} \mathrm{Fe} / \mathrm{mL}$ ), a significant induction of chemotaxis was detected. It must be noted, however, that the concentrations of iron oxide nanoparticles are traditionally normalized to the total iron content, so the concentrations used here correspond to a much higher total dry mass weight e.g. about 10-fold higher in case of dextran-coated IO-NP4. 
Concerning IO-NP3, no major effects of these particles either on endothelial-monocytic interactions, or monocytic cell chemotaxis were observed. Decreased numbers of adherent monocytic cells were detected in the samples treated with $100 \mu \mathrm{g} / \mathrm{mL}$ IO-NP3, but not at $400 \mu \mathrm{g} / \mathrm{mL}$. At this highest tested concentration, a slight, but not significant, increase in monocytic cell chemotaxis was also observable. However, IO-NP3 had a strong negative effect on endothelial migration, significantly and dosedependently increasing the time of gap closure. As previously reported by Soenen et al., high intracellular concentrations of certain iron oxide-based nanoparticles induce strong polarization of endothelial cells and affect actin cytoskeleton and microtubule network reorganization (Soenen, et al., 2010). This effect was also observed in our studies, in particular in IO-NP1 and IO-NP3-treated HUVECs, which showed reduced cell spreading and strongly limited migratory capacity.

Taken together, our studies showed different nanoparticle type- and concentration- dependent effects and effects of the nanoparticle-loaded drug on endothelial and monocytic cell functions. In the performed assays, PEG-ylated liposomes and dextran-coated USPIO demonstrated the least toxicity among the tested nanosystems, indicating their potential for use in therapy and /or diagnosis of CVD. Generally, the majority of the responses observed in unloaded nanoparticles can be considered mainly as nanoparticle type-dependent effects, but even among the particles of the same type (e.g. LD-NPs, PM-NPs or IO-NPs), the degree of exerted effect can vary, indicating that both nanoparticle toxicity and their non-cytotoxic biological effects depend on many characteristics apart from composition of the core. As an example, among the tested lipid nanoparticles, the best tolerated formulation was the one with largest diameter, thus the smallest surfactant to core ratio. It is known that certain physicochemical characteristics of nanoparticles can serve as predictors of increased toxicity (e.g. positive charge facilitating cellular uptake, aggregation tendency) and should be carefully avoided when designing a nanosystem for potential clinical application. Additionally, nanoparticle coating appears to play a major role in the cellular response to nanosystems. This may be due to the type of coating (composition), but also due to insufficient coating density or stability that can result in the exposure of the unmodified surface to cells. Therefore, each modification introduced in "basic" particle composition, size and coating should be treated with caution and ideally tested anew for potential toxicity and cellular effects. 


\section{Conclusions}

Our studies advance the nanosafety by providing new insights into the nanoparticle effects on human endothelial and monocytic cells. Although the majority of the tested nanosystems had favourable biocompatibility profiles for potential cardiovascular imaging and drug-targeting, their specific effects on endothelial and monocytic cell functions should be taken into account when considering in vivo application. In many cases, the conjugated drug or compound was clearly responsible for the characteristic cellular effects of particles. Currently, testing of the most promising candidates for procoagulant activity and complement activation is ongoing, but a substantial amount of in vivo studies is necessary before the nanosystems with proven in vitro safety and efficacy can be translated into clinical trials. Despite multiple regulatory constraints, the future progress in diagnosis and treatment of cardiovascular disorders is expected to benefit strongly from the development of novel nanotechnologybased strategies.

\section{Acknowledgements}

The authors thank Prof. Beckmann (Dept. of Gynaecology, University Hospital Erlangen, Germany) for providing umbilical cords. We also thank Heike Kloos and Doris Flick (Laboratory of Molecular Cardiology, University Hospital Erlangen, Germany) for help with HUVEC isolation. Technical help of Julia Band is gratefully acknowledged.

\section{Funding}

This work was supported by the EU (“NanoAthero” project FP7-NMP-2012-LARGE-6-309820), the DFG (CI 162/2-1), and received the financial support from ANR-13-LAB1-0005-01 "FucoChem". 
LETI/DTBS is part of the Arcane Labex program, funded by the French National Research Agency

(ARCANE project n ANR-12-LABX-003).

\section{Disclosure statement}

The authors have no conflict of interests to disclose.

\section{References}

H. Mangge, G. Almer, I. Stelzer, E. Reininghaus and R. Prassl. 2014. Laboratory medicine for molecular imaging of atherosclerosis. Clinica chimica acta; international journal of clinical chemistry 437:19-24. R. Lozano, M. Naghavi, K. Foreman, S. Lim, K. Shibuya, V. Aboyans, J. Abraham, T. Adair, R. Aggarwal, S. Y. Ahn, M. Alvarado, H. R. Anderson, L. M. Anderson, K. G. Andrews, C. Atkinson, L. M. Baddour, S. Barker-Collo, D. H. Bartels, M. L. Bell, E. J. Benjamin, D. Bennett, K. Bhalla, B. Bikbov, A. Bin Abdulhak, G. Birbeck, F. Blyth, I. Bolliger, S. Boufous, C. Bucello, M. Burch, P. Burney, J. Carapetis, H. Chen, D. Chou, S. S. Chugh, L. E. Coffeng, S. D. Colan, S. Colquhoun, K. E. Colson, J. Condon, M. D. Connor, L. T. Cooper, M. Corriere, M. Cortinovis, K. C. de Vaccaro, W. Couser, B. C. Cowie, M. H. Criqui, M. Cross, K. C. Dabhadkar, N. Dahodwala, D. De Leo, L. Degenhardt, A. Delossantos, J. Denenberg, D. C. Des Jarlais, S. D. Dharmaratne, E. R. Dorsey, T. Driscoll, H. Duber, B. Ebel, P. J. Erwin, P. Espindola, M. Ezzati, V. Feigin, A. D. Flaxman, M. H. Forouzanfar, F. G. Fowkes, R. Franklin, M. Fransen, M. K. Freeman, S. E. Gabriel, E. Gakidou, F. Gaspari, R. F. Gillum, D. Gonzalez-Medina, Y. A. Halasa, D. Haring, J. E. Harrison, R. Havmoeller, R. J. Hay, B. Hoen, P. J. Hotez, D. Hoy, K. H. Jacobsen, S. L. James, R. Jasrasaria, S. Jayaraman, N. Johns, G. Karthikeyan, N. Kassebaum, A. Keren, J. P. Khoo, L. M. Knowlton, O. Kobusingye, A. Koranteng, R. Krishnamurthi, M. Lipnick, S. E. Lipshultz, S. L. Ohno, J. Mabweijano, M. F. Maclntyre, L. Mallinger, L. March, G. B. Marks, R. Marks, A. Matsumori, R. Matzopoulos, B. M. Mayosi, J. H. McAnulty, M. M. McDermott, J. McGrath, G. A. Mensah, T. R. Merriman, C. Michaud, M. Miller, T. R. Miller, C. Mock, A. O. Mocumbi, A. A. Mokdad, A. Moran, K. Mulholland, M. N. Nair, L. Naldi, K. M. Narayan, K. Nasseri, P. Norman, M. O'Donnell, S. B. Omer, K. Ortblad, R. Osborne, D. Ozgediz, B. Pahari, J. D. Pandian, A. P. Rivero, R. P. Padilla, F. Perez-Ruiz, N. Perico, D. Phillips, K. Pierce, C. A. Pope, 3rd, E. Porrini, F. Pourmalek, M. Raju, D. Ranganathan, J. T. Rehm, D. B. Rein, G. Remuzzi, F. P. Rivara, T. Roberts, F. R. De Leon, L. C. Rosenfeld, L. Rushton, R. L. Sacco, J. A. Salomon, U. Sampson, E. Sanman, D. C. Schwebel, M. Segui-Gomez, D. S. Shepard, D. Singh, J. Singleton, K. Sliwa, E. Smith, A. Steer, J. A. Taylor, B. Thomas, I. M. Tleyjeh, J. A. Towbin, T. Truelsen, E. A. Undurraga, N. Venketasubramanian, L. Vijayakumar, T. Vos, G. R. Wagner, M. Wang, W. Wang, K. Watt, M. A. Weinstock, R. Weintraub, J. D. Wilkinson, A. D. Woolf, S. Wulf, P. H. Yeh, P. Yip, A. Zabetian, Z. J. Zheng, A. D. Lopez, C. J. Murray, M. A. AlMazroa and Z. A. Memish. 2012. Global and regional mortality from 235 causes of death for 20 age groups in 1990 and 2010: a systematic analysis for the Global Burden of Disease Study 2010. Lancet 380:2095-2128.

J. Hamzah, V. R. Kotamraju, J. W. Seo, L. Agemy, V. Fogal, L. M. Mahakian, D. Peters, L. Roth, M. K. Gagnon, K. W. Ferrara and E. Ruoslahti. 2011. Specific penetration and accumulation of a homing peptide within atherosclerotic plaques of apolipoprotein E-deficient mice. Proceedings of the National Academy of Sciences of the United States of America 108:7154-7159.

I. Cicha, C. D. Garlichs and C. Alexiou. 2014. Cardiovascular therapy through nanotechnology - how far are we still from bedside? Eur J Nanomed 6:63-87.

M. Bietenbeck, A. Florian, C. Faber, U. Sechtem and A. Yilmaz. 2016. Remote magnetic targeting of iron oxide nanoparticles for cardiovascular diagnosis and therapeutic drug delivery: where are we now? International journal of nanomedicine 11:3191-3203. 
M. Karimi, H. Zare, A. Bakhshian Nik, N. Yazdani, M. Hamrang, E. Mohamed, P. Sahandi Zangabad, S. M. Moosavi Basri, L. Bakhtiari and M. R. Hamblin. 2016. Nanotechnology in diagnosis and treatment of coronary artery disease. Nanomedicine (Lond) 11:513-530.

J. Matuszak, J. Baumgartner, J. Zaloga, M. Juenet, A. E. da Silva, D. Franke, G. Almer, I. Texier, D. Faivre, J. M. Metselaar, F. P. Navarro, C. Chauvierre, R. Prassl, L. Dezsi, R. Urbanics, C. Alexiou, H. Mangge, J. Szebeni, D. Letourneur and I. Cicha. 2016. Nanoparticles for intravascular applications: physicochemical characterization and cytotoxicity testing. Nanomedicine (Lond) 11:597-616.

I. Cicha, K. Beronov, E. L. Ramirez, K. Osterode, M. Goppelt-Struebe, D. Raaz, A. Yilmaz, W. G. Daniel and C. D. Garlichs. 2009. Shear stress preconditioning modulates endothelial susceptibility to circulating TNF-alpha and monocytic cell recruitment in a simplified model of arterial bifurcations. Atherosclerosis 207:93-102.

A. Puri, K. Loomis, B. Smith, J. H. Lee, A. Yavlovich, E. Heldman and R. Blumenthal. 2009. Lipid-based nanoparticles as pharmaceutical drug carriers: from concepts to clinic. Critical reviews in therapeutic drug carrier systems 26:523-580.

G. Almer, K. Wernig, M. Saba-Lepek, S. Haj-Yahya, J. Rattenberger, J. Wagner, K. Gradauer, D. Frascione, G. Pabst, G. Leitinger, H. Mangge, A. Zimmer and R. Prassl. 2011. Adiponectin-coated nanoparticles for enhanced imaging of atherosclerotic plaques. International journal of nanomedicine 6:1279-1290.

G. Almer, D. Frascione, I. Pali-Scholl, C. Vonach, A. Lukschal, C. Stremnitzer, S. C. Diesner, E. JensenJarolim, R. Prassl and H. Mangge. 2013. Interleukin-10: an anti-inflammatory marker to target atherosclerotic lesions via PEGylated liposomes. Molecular pharmaceutics 10:175-186.

T. van der Geest, J. M. Metselaar, D. Gerrits, P. L. van Lent, G. Storm, P. Laverman and O. C. Boerman. 2015. [(18)]F FDG PET/CT imaging to monitor the therapeutic effect of liposome-encapsulated prednisolone in experimental rheumatoid arthritis. Journal of Controlled Release 209:20-26.

J. Gravier, F. P. Navarro, T. Delmas, F. Mittler, A. C. Couffin, F. Vinet and I. Texier. 2011. Lipidots: competitive organic alternative to quantum dots for in vivo fluorescence imaging. Journal of biomedical optics 16:096013.

C. Chauvierre, D. Labarre, P. Couvreur and C. Vauthier. 2003. Radical emulsion polymerization of alkylcyanoacrylates initiated by the redox system dextran-cerium(IV) under acidic aqueous conditions. Macromolecules 36:6018-6027.

L. Bachelet, I. Bertholon, D. Lavigne, R. Vassy, M. Jandrot-Perrus, F. Chaubet and D. Letourneur. 2009. Affinity of low molecular weight fucoidan for P-selectin triggers its binding to activated human platelets. Biochimica et biophysica acta 1790:141-146.

F. Rouzet, L. Bachelet-Violette, J. M. Alsac, M. Suzuki, A. Meulemans, L. Louedec, A. Petiet, M. JandrotPerrus, F. Chaubet, J. B. Michel, D. Le Guludec and D. Letourneur. 2011. Radiolabeled fucoidan as a pselectin targeting agent for in vivo imaging of platelet-rich thrombus and endothelial activation. Journal of nuclear medicine : official publication, Society of Nuclear Medicine 52:1433-1440.

J. Zaloga, C. Janko, J. Nowak, J. Matuszak, S. Knaup, D. Eberbeck, R. Tietze, H. Unterweger, R. P. Friedrich, S. Duerr, R. Heimke-Brinck, E. Baum, I. Cicha, F. Dorje, S. Odenbach, S. Lyer, G. Lee and C. Alexiou. 2014. Development of a lauric acid/albumin hybrid iron oxide nanoparticle system with improved biocompatibility. International journal of nanomedicine 9:4847-4866.

H. Unterweger, R. Tietze, C. Janko, J. Zaloga, S. Lyer, S. Durr, N. Taccardi, O. M. Goudouri, A. Hoppe, D. Eberbeck, D. W. Schubert, A. R. Boccaccini and C. Alexiou. 2014. Development and characterization of magnetic iron oxide nanoparticles with a cisplatin-bearing polymer coating for targeted drug delivery. International journal of nanomedicine 9:3659-3676.

H. Unterweger, C. Janko, M. Schwarz, L. Dezsi, R. Urbanics, J. Matuszak, E. Orfi, T. Fulop, T. Bauerle, J. Szebeni, C. Journe, A. R. Boccaccini, C. Alexiou, S. Lyer and I. Cicha. 2017. Non-immunogenic dextrancoated superparamagnetic iron oxide nanoparticles: a biocompatible, size-tunable contrast agent for magnetic resonance imaging. International journal of nanomedicine 12:5223-5238.

A. Kumar and A. Dhawan. 2013. Genotoxic and carcinogenic potential of engineered nanoparticles: an update. Archives of toxicology 87:1883-1900.

B. S. Zolnik, A. Gonzalez-Fernandez, N. Sadrieh and M. A. Dobrovolskaia. 2010. Nanoparticles and the immune system. Endocrinology 151:458-465. 
N. Desai. 2012. Challenges in development of nanoparticle-based therapeutics. The AAPS journal 14:282-295.

J. Huwyler, J. Drewe and S. Krahenbuhl. 2008. Tumor targeting using liposomal antineoplastic drugs. International journal of nanomedicine 3:21-29.

R. H. Muller, R. Shegokar and C. M. Keck. 2011. 20 years of lipid nanoparticles (SLN and NLC): present state of development and industrial applications. Current drug discovery technologies 8:207-227.

P. J. Wermuth and S. A. Jimenez. 2014. Induction of a type I interferon signature in normal human monocytes by gadolinium-based contrast agents: comparison of linear and macrocyclic agents. Clinical and experimental immunology 175:113-125.

M. Pozo, R. de Nicolas, J. Egido and J. Gonzalez-Cabrero. 2006. Simvastatin inhibits the migration and adhesion of monocytic cells and disorganizes the cytoskeleton of activated endothelial cells. European journal of pharmacology 548:53-63.

M. Gelati, E. Corsini, A. Dufour, E. Ciusani, G. Massa, S. Frigerio, C. Milanese, A. Nespolo and A. Salmaggi. 1997. Reduced adhesion of PBMNCs to endothelium in methylprednisolone-treated MS patients: preliminary results. Acta neurologica Scandinavica 96:283-292.

T. Simoncini, S. Maffei, G. Basta, G. Barsacchi, A. R. Genazzani, J. K. Liao and R. De Caterina. 2000. Estrogens and glucocorticoids inhibit endothelial vascular cell adhesion molecule-1 expression by different transcriptional mechanisms. Circulation research 87:19-25.

S. Katsuki, T. Matoba, S. Nakashiro, K. Sato, J. Koga, K. Nakano, Y. Nakano, S. Egusa, K. Sunagawa and K. Egashira. 2014. Nanoparticle-mediated delivery of pitavastatin inhibits atherosclerotic plaque destabilization/rupture in mice by regulating the recruitment of inflammatory monocytes. Circulation 129:896-906.

B. Wong, W. C. Lumma, A. M. Smith, J. T. Sisko, S. D. Wright and T. Q. Cai. 2001. Statins suppress THP1 cell migration and secretion of matrix metalloproteinase 9 by inhibiting geranylgeranylation. Journal of leukocyte biology 69:959-962.

T. Courant, E. Bayon, H. L. Reynaud-Dougier, C. Villiers, M. Menneteau, P. N. Marche and F. P. Navarro. 2017. Tailoring nanostructured lipid carriers for the delivery of protein antigens: Physicochemical properties versus immunogenicity studies. Biomaterials 136:29-42.

J. Merian, R. Boisgard, X. Decleves, B. Theze, I. Texier and B. Tavitian. 2013. Synthetic Lipid Nanoparticles Targeting Steroid Organs. Journal of Nuclear Medicine 54:1996-2003.

T. M. Goppert and R. H. Muller. 2005. Adsorption kinetics of plasma proteins on solid lipid nanoparticles for drug targeting. Int J Pharm 302:172-186.

T. M. Goppert and R. H. Muller. 2005. Protein adsorption patterns on poloxamer- and poloxaminestabilized solid lipid nanoparticles (SLN). European Journal of Pharmaceutics and Biopharmaceutics 60:361-372.

S. Mura and P. Couvreur. 2012. Nanotheranostics for personalized medicine. Advanced drug delivery reviews 64:1394-1416.

C. Chauvierre, D. Labarre, P. Couvreur and C. Vauthier. 2003. Novel polysaccharide-decorated poly(isobutyl cyanoacrylate) nanoparticles. Pharmaceutical research 20:1786-1793.

R. H. Muller, C. Lherm, J. Herbort and P. Couvreur. 1990. Invitro Model for the Degradation of Alkylcyanoacrylate Nanoparticles. Biomaterials 11:590-595.

C. C. Berry and A. S. G. Curtis. 2003. Functionalisation of magnetic nanoparticles for applications in biomedicine. J Phys D Appl Phys 36:R198-R206.

G. Sun and J. J. Mao. 2012. Engineering dextran-based scaffolds for drug delivery and tissue repair. Nanomedicine 7:1771-1784.

T. R. Porter. 2007. Cardiovascular imaging of remote myocardial ischemia: detecting a molecular trace of evidence left behind. Circulation 115:292-293.

P. Libby, M. DiCarli and R. Weissleder. 2010. The vascular biology of atherosclerosis and imaging targets. J Nucl Med 51 Suppl 1:33S-37S.

M. J. Polley, M. L. Phillips, E. Wayner, E. Nudelman, A. K. Singhal, S. I. Hakomori and J. C. Paulson. 1991. Cd62 and Endothelial-Cell Leukocyte Adhesion Molecule-1 (Elam-1) Recognize the Same Carbohydrate Ligand, Sialyl-Lewis-X. P Natl Acad Sci USA 88:6224-6228. 
M. Heinzelmann, H. C. Polk, Jr. and F. N. Miller. 1998. Modulation of lipopolysaccharide-induced monocyte activation by heparin-binding protein and fucoidan. Infection and immunity 66:5842-5847. W. F. Zandberg, J. Kumarasamy, B. M. Pinto and D. J. Vocadlo. 2012. Metabolic inhibition of sialyl-Lewis $\mathrm{X}$ biosynthesis by 5 -thiofucose remodels the cell surface and impairs selectin-mediated cell adhesion. The Journal of biological chemistry 287:40021-40030.

A. Cumashi, N. A. Ushakova, M. E. Preobrazhenskaya, A. D'Incecco, A. Piccoli, L. Totani, N. Tinari, G. E. Morozevich, A. E. Berman, M. I. Bilan, A. I. Usov, N. E. Ustyuzhanina, A. A. Grachev, C. J. Sanderson, M. Kelly, G. A. Rabinovich, S. Iacobelli, N. E. Nifantiev and I. Consorzio Interuniversitario Nazionale per la Bio-Oncologia. 2007. A comparative study of the anti-inflammatory, anticoagulant, antiangiogenic, and antiadhesive activities of nine different fucoidans from brown seaweeds. Glycobiology 17:541-552.

R. A. Trivedi, C. Mallawarachi, U. K.-I. JM, M. J. Graves, J. Horsley, M. J. Goddard, A. Brown, L. Wang, P. J. Kirkpatrick, J. Brown and J. H. Gillard. 2006. Identifying inflamed carotid plaques using in vivo USPIOenhanced MR imaging to label plaque macrophages. Arteriosclerosis, thrombosis, and vascular biology 26:1601-1606.

S. P. Howarth, T. Y. Tang, R. Trivedi, R. Weerakkody, U. K.-I. J, M. E. Gaunt, J. R. Boyle, Z. Y. Li, S. R. Miller, M. J. Graves and J. H. Gillard. 2009. Utility of USPIO-enhanced MR imaging to identify inflammation and the fibrous cap: a comparison of symptomatic and asymptomatic individuals. European journal of radiology 70:555-560.

T. Y. Tang, K. H. Muller, M. J. Graves, Z. Y. Li, S. R. Walsh, V. Young, U. Sadat, S. P. Howarth and J. H. Gillard. 2009. Iron oxide particles for atheroma imaging. Arteriosclerosis, thrombosis, and vascular biology 29:1001-1008.

U. Sadat, S. P. Howarth, A. Usman, T. Y. Tang, M. J. Graves and J. H. Gillard. 2013. Sequential Imaging of Asymptomatic Carotid Atheroma Using Ultrasmall Superparamagnetic Iron Oxide-enhanced Magnetic Resonance Imaging: A Feasibility Study. Journal of stroke and cerebrovascular diseases : the official journal of National Stroke Association 22:e271-276.

J. M. Richards, C. A. Shaw, N. N. Lang, M. C. Williams, S. I. Semple, T. J. MacGillivray, C. Gray, J. H. Crawford, S. R. Alam, A. P. Atkinson, E. K. Forrest, C. Bienek, N. L. Mills, A. Burdess, K. Dhaliwal, A. J. Simpson, W. A. Wallace, A. T. Hill, P. H. Roddie, G. McKillop, T. A. Connolly, G. Z. Feuerstein, G. R. Barclay, M. L. Turner and D. E. Newby. 2012. In vivo mononuclear cell tracking using superparamagnetic particles of iron oxide: feasibility and safety in humans. Circulation Cardiovascular imaging 5:509-517.

C. Janko, S. Durr, L. E. Munoz, S. Lyer, R. Chaurio, R. Tietze, S. Lohneysen, C. Schorn, M. Herrmann and C. Alexiou. 2013. Magnetic drug targeting reduces the chemotherapeutic burden on circulating leukocytes. International journal of molecular sciences 14:7341-7355.

S. Lyer, R. Tietze, R. Jurgons, T. Struffert, T. Engelhorn, E. Schreiber, A. Dorfler and C. Alexiou. 2010. Visualisation of tumour regression after local chemotherapy with magnetic nanoparticles - a pilot study. Anticancer research 30:1553-1557.

R. Tietze, S. Lyer, S. Durr, T. Struffert, T. Engelhorn, M. Schwarz, E. Eckert, T. Goen, S. Vasylyev, W. Peukert, F. Wiekhorst, L. Trahms, A. Dorfler and C. Alexiou. 2013. Efficient drug-delivery using magnetic nanoparticles--biodistribution and therapeutic effects in tumour bearing rabbits. Nanomedicine 9:961971.

W. J. Zhang and B. Frei. 2002. Albumin selectively inhibits TNF alpha-induced expression of vascular cell adhesion molecule-1 in human aortic endothelial cells. Cardiovasc Res 55:820-829.

A. C. Desfaits, O. Serri and G. Renier. 1999. Gliclazide reduces the induction of human monocyte adhesion to endothelial cells by glycated albumin. Diabetes, obesity \& metabolism 1:113-120.

S. J. H. Soenen, N. Nuytten, S. F. De Meyer, S. C. De Smedt and M. De Cuyper. 2010. High Intracellular Iron Oxide Nanoparticle Concentrations Affect Cellular Cytoskeleton and Focal Adhesion KinaseMediated Signaling. Small 6:832-842. 


\section{Figure Legends}

Figure 1. The effects of tested nanosystems on HUVEC viability, monitrored by real-time cell analysis and live-cell microscopy (up to $72 \mathrm{~h}$ ), and on HUVEC confluence under flow conditions (18 h incubation). The following labels are used: dark green: no toxicity at $400 \mu \mathrm{g} / \mathrm{mL}$; light green: no toxicity at $200 \mu \mathrm{g} / \mathrm{mL}$; off-white: toxicity at/below $200 \mu \mathrm{g} / \mathrm{mL}$; red: toxicity at and below $100 \mu \mathrm{g} / \mathrm{mL}$. LOEL (lowest concentration with significant toxic effect levels) values are indicated in the figure for non-green range nanosystems.

Figure 2. Effects of circulating nanoparticles on monocytic cell recruitment by HUVECs. HUVECs in bifurcation flow through slides were perfused with indicated concentrations of nanoparticles for $18 \mathrm{~h}$, followed by stimulation with TNF- $\alpha$ (2h). Adherent monocytic cells were quantified after $1 \mathrm{~h}$ of dynamic adhesion assay in at least 8 microscopic images per experiment (non-uniform region, 10x objective magnification). Graphs show numbers of monocytic cells recruited by HUVECs pretreated with circulating (A) LP-NP1; (B) LP-NP2; (C) LD-NPs; (D) PM-NPs and (E) IO-NPs. Numbers of adherent cells in non-uniform shear stress region of control (nanoparticle-untreated) samples were set to $100 \%$. Data are expressed as mean \pm SEM. ${ }^{*} \mathrm{p}<0.05 ;{ }^{* * *} \mathrm{p}<0.001$ vs. control; t-test or signed rank test; $\mathrm{n}=3-5$ experiments with 8 representative images each.

Figure 3. Effect of nanoparticles on spontaneous HUVEC migration. HUVECs were pre-treated with 0, 50 or $100 \mu \mathrm{g} / \mathrm{mL}$ LD-NPs (A), PM-NPs (B), or IO-NPs (C) for $24 \mathrm{~h}$. A gap between two cell layers was created using a cell culture insert. After removal of the insert, HUVECs were washed and further incubated with medium containing the appropriate concentrations of nanoparticles. Cell migration was 
monitored for $24 \mathrm{~h}$. Analysis was performed with ImageJ. Data are expressed as mean $\pm \mathrm{SEM} .{ }^{*} \mathrm{p}<0.05$; ${ }^{* *} \mathrm{p}<0.01 ;{ }^{* * *} \mathrm{p}<0.001$ vs. control; t-test or signed rank test; $\mathrm{n}=3-4$ experiments with duplicate samples and 3 images per well (whole length of gap).

Figure 4. Effects of lipid-based nanoparticles on monocytic cell chemotaxis. THP-1 chemotaxis towards MCP-1 after treatment with LP-NP1 (A), LP-NP2 (B), or LD-NPs (C) for $2 \mathrm{~h}$ was quantified. Number of migrated cells in positive control samples was set to $100 \%$. Data are expressed as mean \pm SEM. ${ }^{* *} \mathrm{p}<0.01 ;{ }^{* * *} \mathrm{p}<0.001$ vs. nanoparticle-untreated positive control; one way ANOVA or ANOVA on ranks; $\mathrm{n}=3$ experiments with quadruplicate samples.

Figure 5. Effects of polymer-based and iron oxide-based nanoparticles on monocytic cell chemotaxis. THP-1 chemotaxis towards MCP-1 after treatment with PM-NPs (A), lauric acid and albumin-coated IO-NPs (B), or dextran-coated IO-NPs (C) for $2 \mathrm{~h}$ was quantified. Shown is the $\mathrm{x}$-fold of negative control (without MCP-1). Data are expressed as mean \pm SEM. ${ }^{* *} \mathrm{p}<0.01 ;{ }^{* * *} \mathrm{p}<0.001$ vs. nanoparticleuntreated positive control; one way ANOVA or ANOVA on ranks; $n=3$ experiments with quadruplicate samples. 
Table 1. Composition and basic physico-chemical characteristics of the tested nanosystems.

\begin{tabular}{|c|c|c|c|c|c|}
\hline Type & $\begin{array}{l}\text { Abbreviated } \\
\text { name }\end{array}$ & Nanoparticle composition & $\begin{array}{c}\text { Z-avg d } \\
(\mathrm{nm})\end{array}$ & $\zeta(\mathrm{mV})$ & PDI \\
\hline \multirow{5}{*}{ Liposome } & LP-NP1 & $\begin{array}{l}\text { Lipid composition: POPC, cholesterol DSPE-PEG2000 } \\
\text { Method: Dry film rehydration }\end{array}$ & 138.6 & -16.3 & 0.104 \\
\hline & Gd-LP-NP1 & $\begin{array}{l}\text { Composition: POPC, cholesterol, DSPE-PEG2000, gadolinium-chelate (B22286) } \\
\text { Method: Dry film rehydration }\end{array}$ & 122.3 & n.d. & 0.040 \\
\hline & LP-NP2 & $\begin{array}{l}\text { Lipid composition: DPPC, DSPE-PEG2000, cholesterol } \\
\text { Method: Lipid injection in the aqueous phase }\end{array}$ & 108.8 & -9.0 & 0.034 \\
\hline & Prava-LP-NP2 & LP-NP2 loaded with pravastatin sodium & 108.0 & -16.1 & 0.080 \\
\hline & Predni-LP-NP2 & LP-NP2 loaded with prednisolone phosphate & 110.0 & -2.7 & 0.070 \\
\hline \multirow{3}{*}{ Lipid NP } & LD-NP1 & $\begin{array}{l}\text { Core: SuppocireTM NB, soybean oil and lipoid S75; Shell: Myrj s40 } \\
\text { Method: Sonication }\end{array}$ & 53.3 & -7.0 & 0.156 \\
\hline & LD-NP2 & $\begin{array}{l}\text { Composition as described for LD-NP1 } \\
\text { Method: Sonication }\end{array}$ & 82.8 & -9.0 & 0.191 \\
\hline & LD-NP3 & $\begin{array}{l}\text { Composition as described for LD-NP1 } \\
\text { Method: Sonication }\end{array}$ & 120.1 & -8.8 & 0.151 \\
\hline \multirow{2}{*}{ Polymer NP } & FC-PM-NP1 & $\begin{array}{l}\text { Core: Poly-isobutylcyanoacrylate (PIBCA); Shell: 90\% carboxymethyl-dextran/ 10\% } \\
\text { Fucoidan } \\
\text { Method: Redox radical emulsion polymerization }\end{array}$ & 145.1 & -51.0 & 0.072 \\
\hline & FC-PM-NP2 & $\begin{array}{l}\text { Core: PIBCA; Shell: } 80 \% \text { dextran T70 /10\% diethylaminoethyl-dextran 20/ } \\
\text { 10\% Fucoidan } \\
\text { Method: Redox radical emulsion polymerization }\end{array}$ & 226.9 & 3.3 & 0.194 \\
\hline \multirow{4}{*}{ Iron oxide NP } & IO-NP1 & $\begin{array}{l}\text { Core: Iron oxide; Shell: Lauric acid/bovine serum albumin } \\
\text { Method: Coprecipitation }\end{array}$ & 78.7 & -37.3 & 0.145 \\
\hline & IO-NP2 & $\begin{array}{l}\text { Core: Iron oxide; Shell: Lauric acid/human serum albumin } \\
\text { Method: Coprecipitation }\end{array}$ & 68.3 & -16.9 & 0.143 \\
\hline & IO-NP3 & $\begin{array}{l}\text { Core: Iron oxide; Shell: Carboxydextran } \\
\text { Method: Coprecipitation }\end{array}$ & 79.6 & 13.7 & 0.173 \\
\hline & IO-NP4 & $\begin{array}{l}\text { Core: Iron oxide; Shell: Dextran T40 } \\
\text { Method: Coprecipitation }\end{array}$ & 30.0 & -6.3 & 0.102 \\
\hline
\end{tabular}

In case of multicore particles (IO-NPs), the Z-Avg value of hydrodynamic diameter refers to the whole multicore clusters, which however do not form aggregates.

Abbreviations: DPPC, dipalmitoylphosphatidylcholine; DSPE-PEG2000, 1,2-distearoyl-phosphatidyl-ethanolamine-methyl-polyethyleneglycol conjugate-2000; POPC, 1-

palmitoyl-2-oleoyl-sn-glycero-3-phosphocholine 
Fig. 1

\begin{tabular}{|l|l|l|l|}
\hline Nanoparticle type & $\begin{array}{c}\text { Real-time } \\
\text { cell analysis }\end{array}$ & $\begin{array}{c}\text { Live-cell } \\
\text { microscopy }\end{array}$ & $\begin{array}{c}\text { Confluence } \\
\text { under flow }\end{array}$ \\
\hline LP-NP1 & & & \\
\hline Gd-LP-NP1 & & & \\
\hline LP-NP2 & & & \\
\hline Prava-LP-NP2 & $100 \mu \mathrm{g} / \mathrm{mL}$ & & \\
\hline Predni-LP-NP2 & & & $100 \mu \mathrm{g} / \mathrm{mL}$ \\
\hline LD-NP1 & & & $100 \mu \mathrm{g} / \mathrm{mL}$ \\
\hline LD-NP2 & $50 \mu \mathrm{g} / \mathrm{mL}$ & $100 \mu \mathrm{g} / \mathrm{mL}$ & \\
\hline LD-NP3 & $100 \mu \mathrm{g} / \mathrm{mL}$ & $100 \mu \mathrm{g} / \mathrm{mL}$ & \\
\hline FC-PM-NP1 & $200 \mu \mathrm{g} / \mathrm{mL}$ & & \\
\hline FC-PM-NP2 & & & \\
\hline IO-NP1 & $200 \mu \mathrm{g} / \mathrm{mL}$ & & \\
\hline IO-NP2 & & & \\
\hline IO-NP3 & & & \\
\hline IO-NP4 & & & \\
\hline
\end{tabular}

\begin{tabular}{|l|l|l|}
\hline no toxicity at $400 \mu \mathrm{g} / \mathrm{mL}$ & & toxicity at/below $200 \mu \mathrm{g} / \mathrm{ml}$ \\
\hline no toxicity at $200 \mu \mathrm{g} / \mathrm{mL}$ & & toxicity at/below $100 \mu \mathrm{g} / \mathrm{mL}$ \\
\hline
\end{tabular}


Fig.2

A

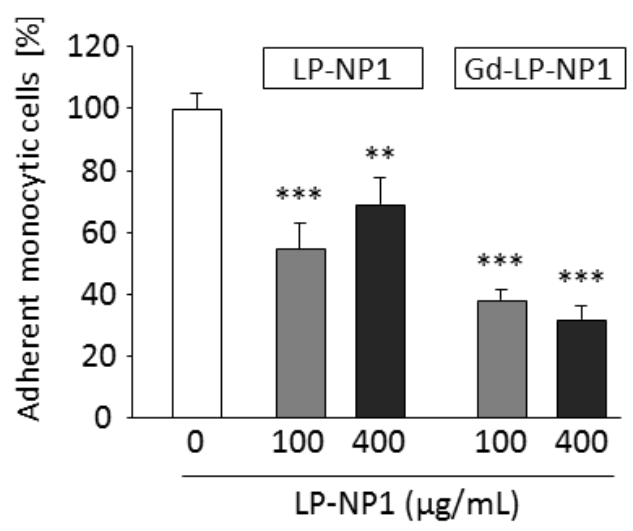

C

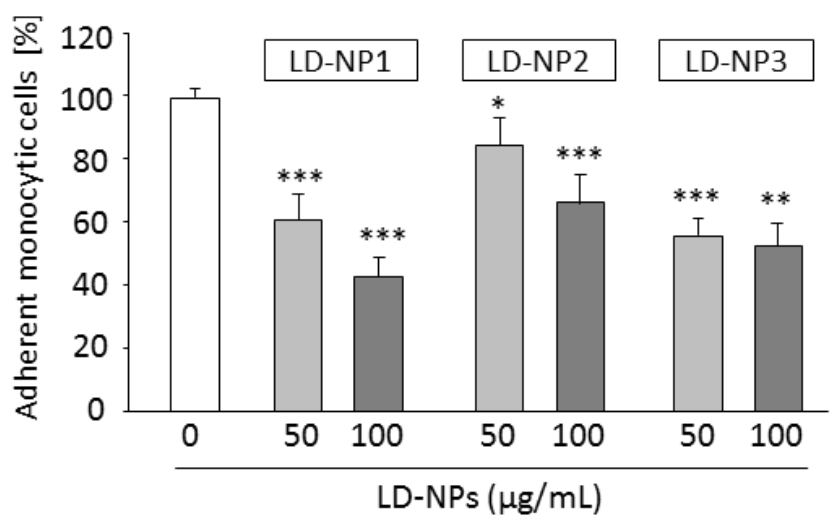

E

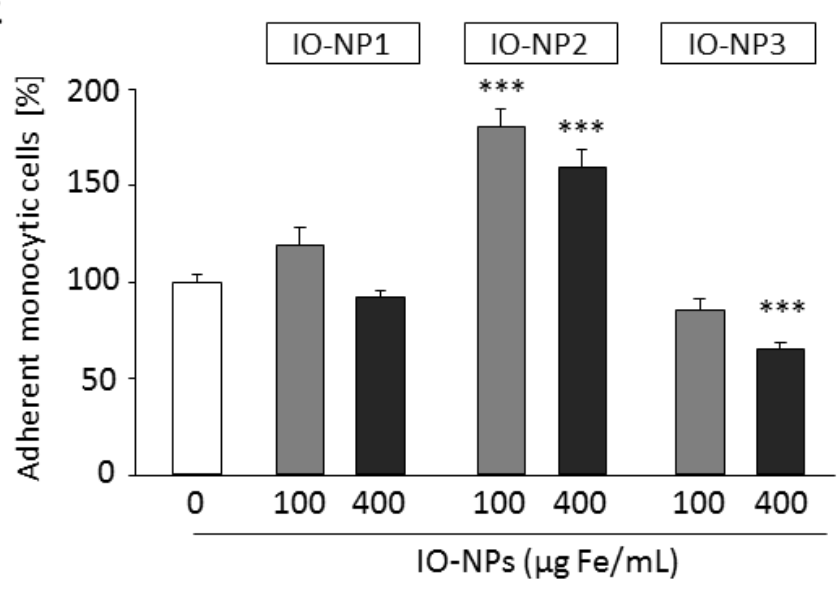

B

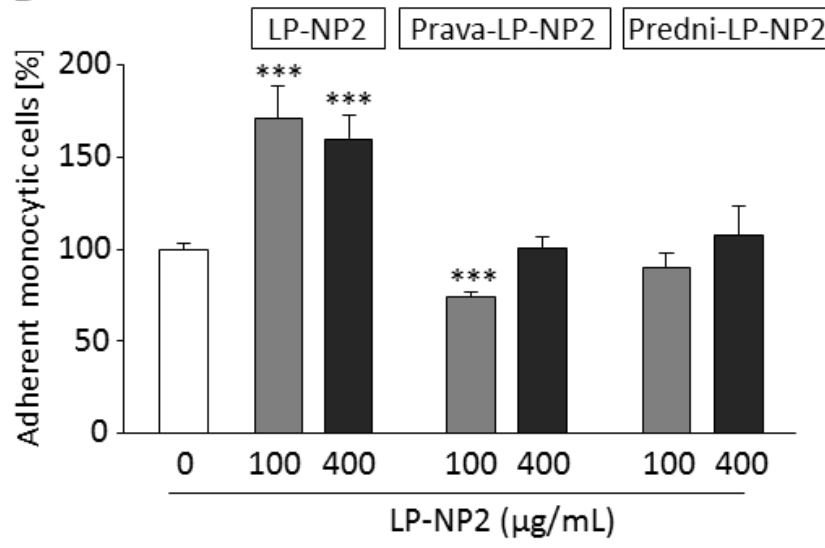

D

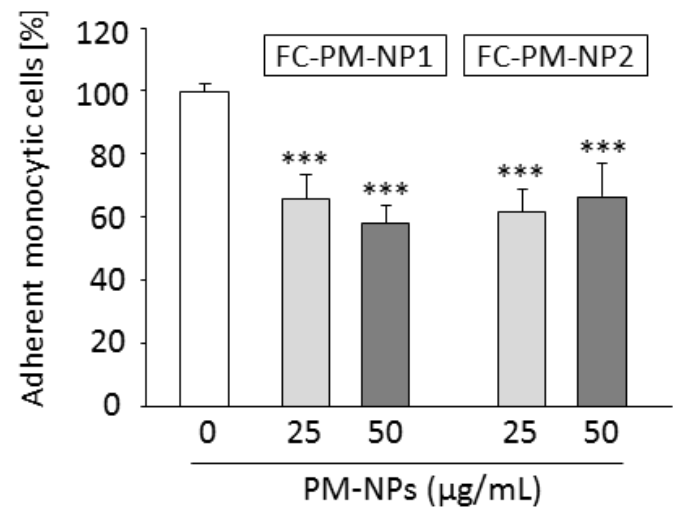


Fig.3
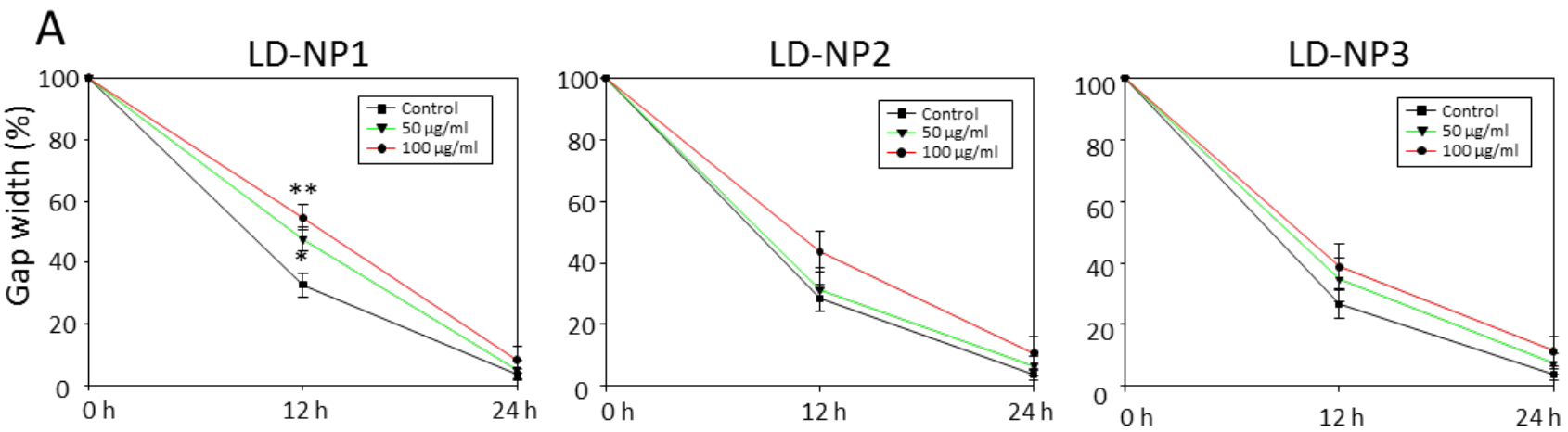

B
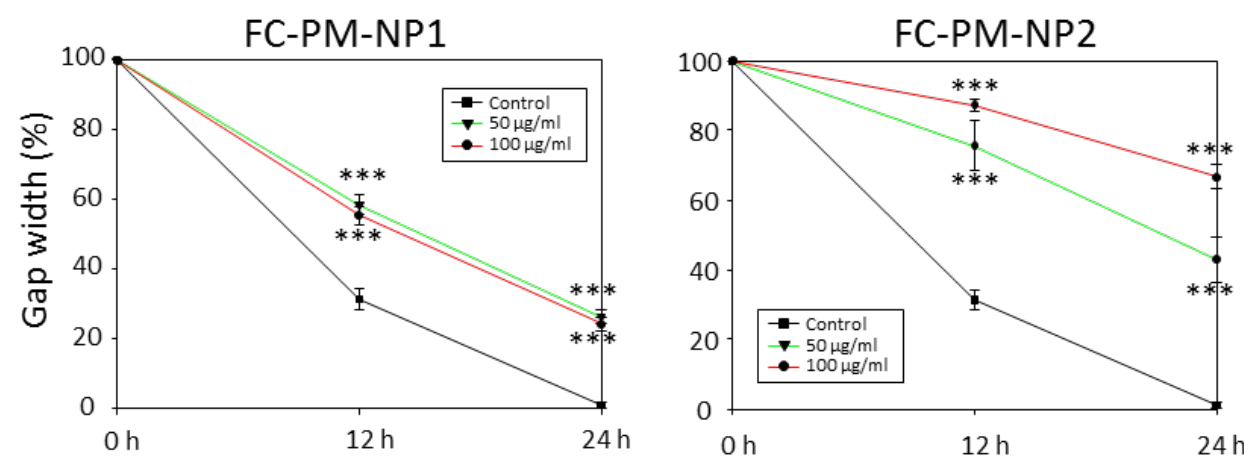

C
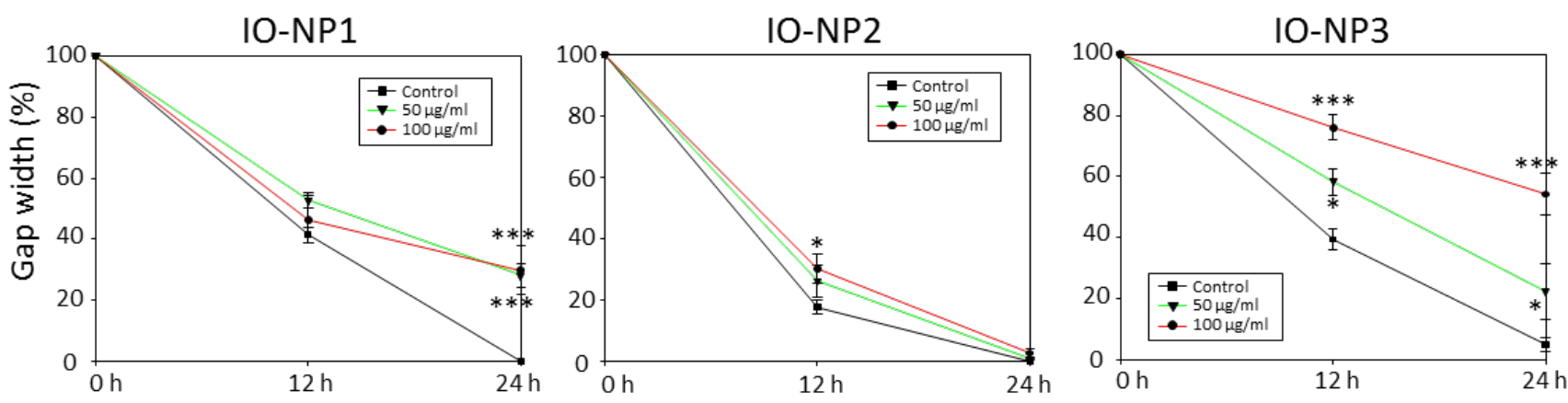
Fig.4

A

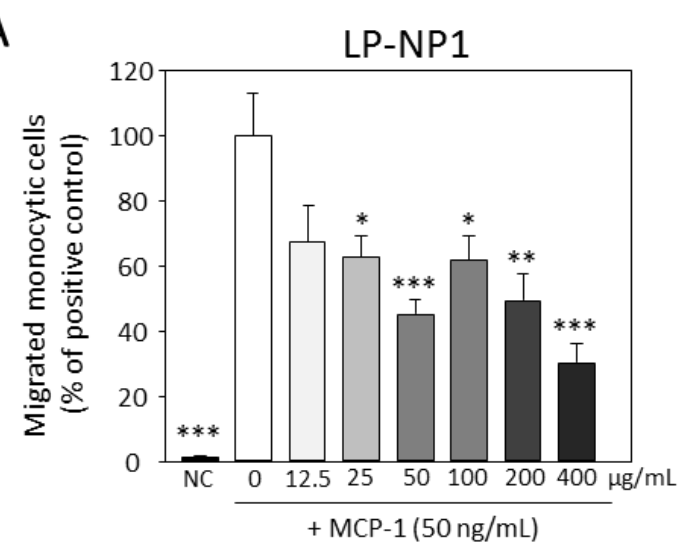

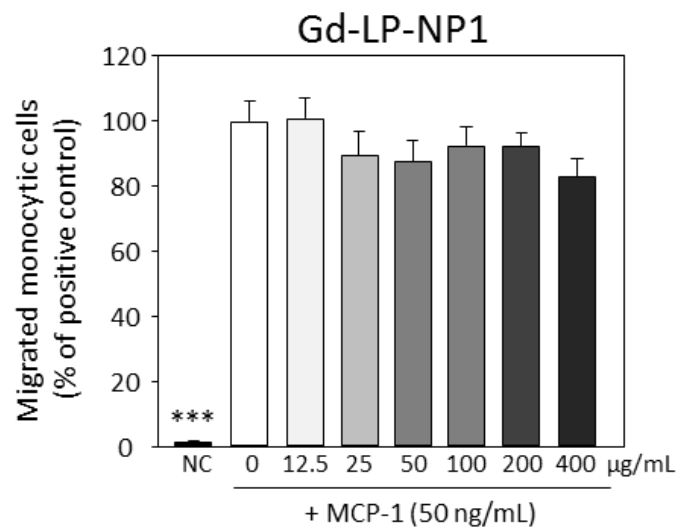

B

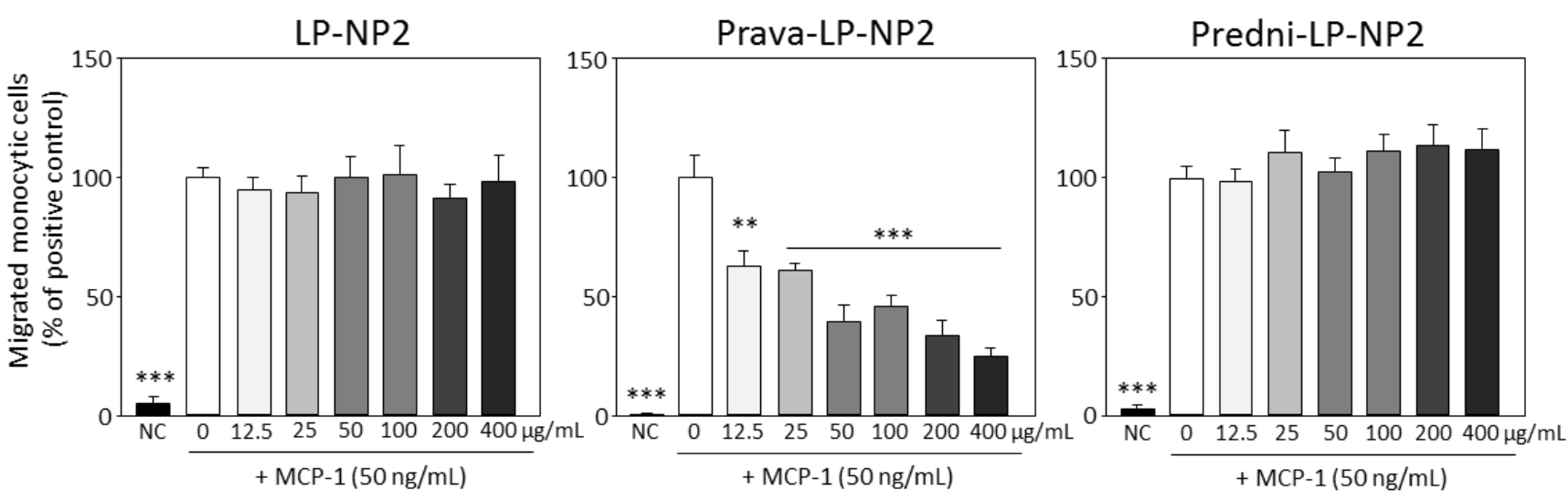

C
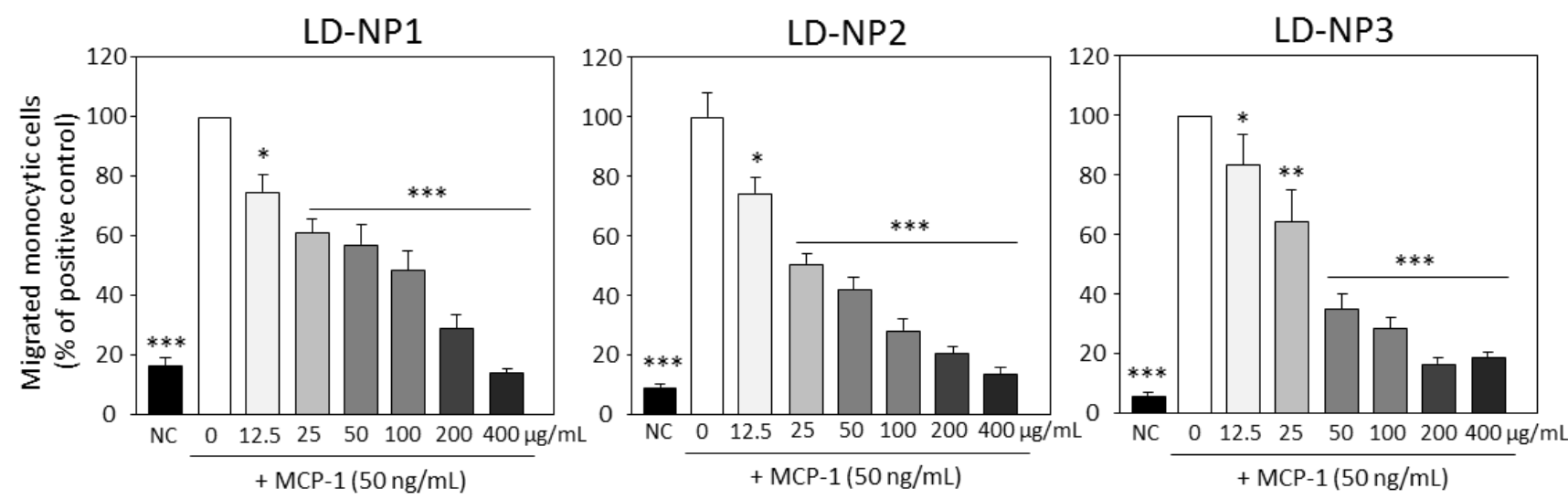
Fig.5

A

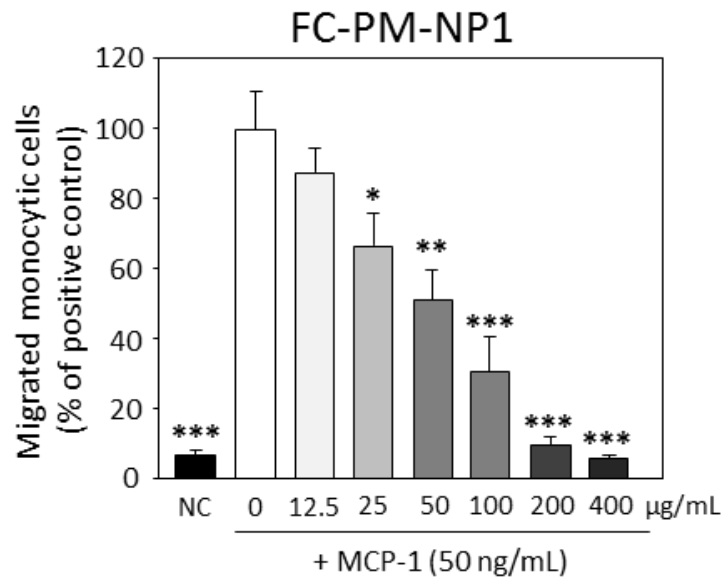

B

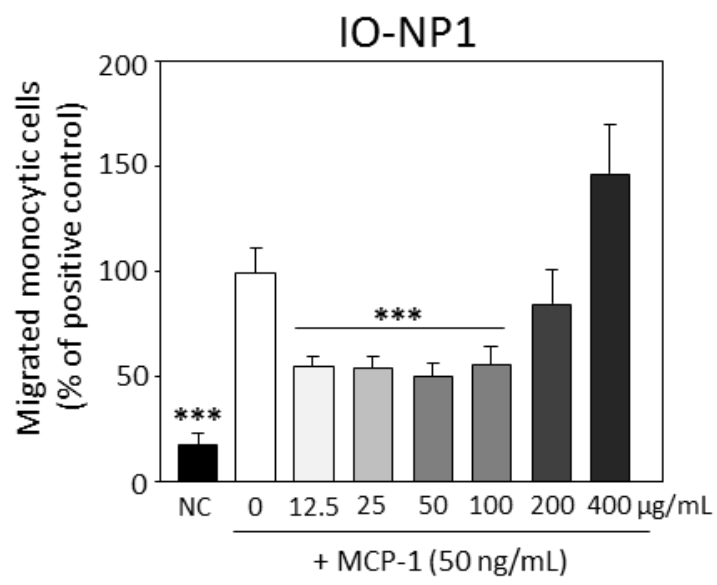

C

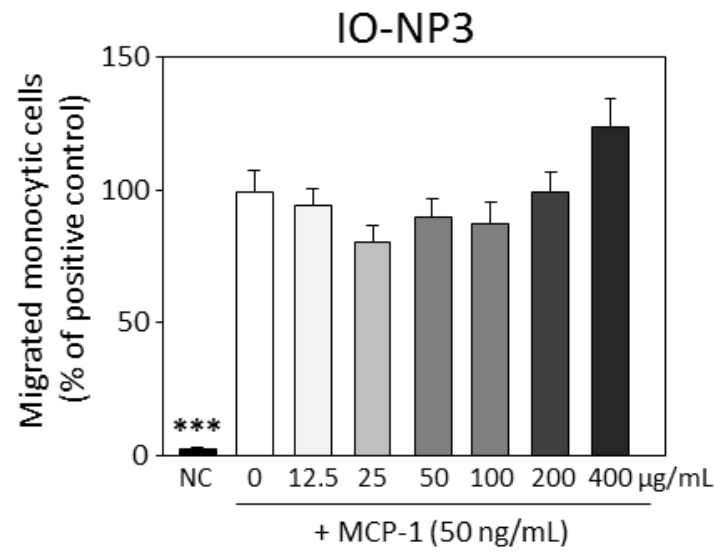

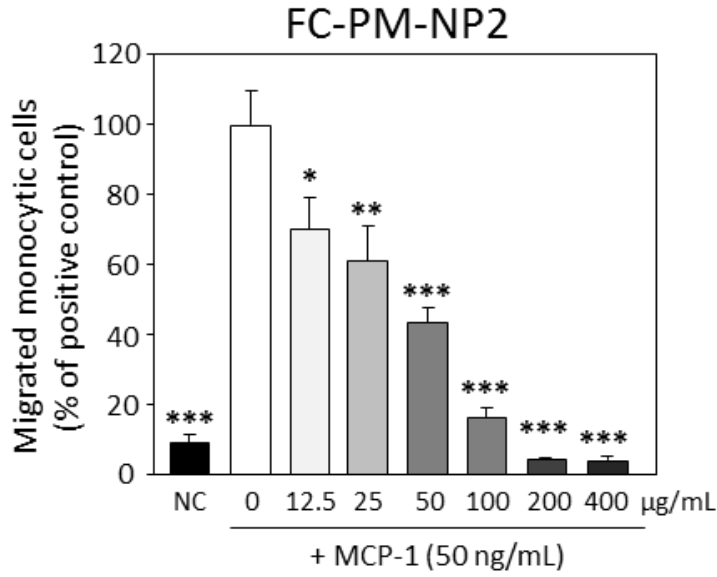
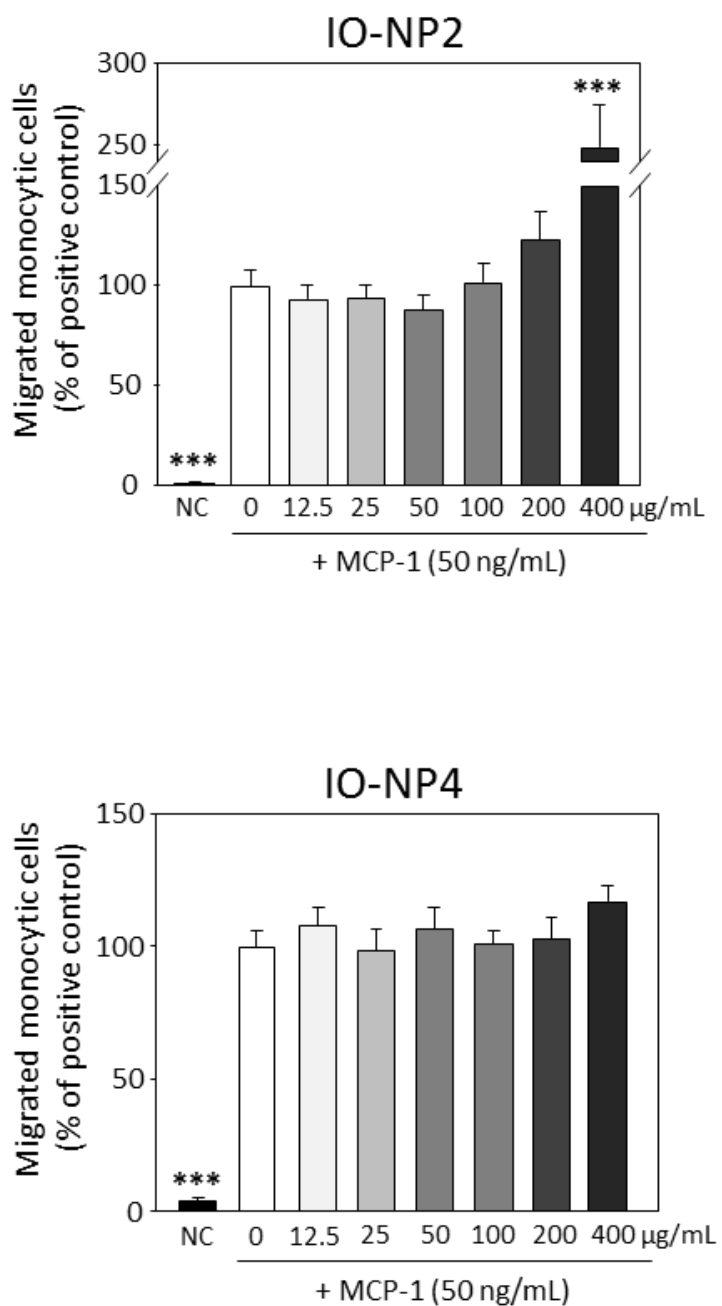


\section{Supplementary data}

\section{Matuszak et al.: Comparative analysis of nanosystems' effects on human endothelial and monocytic cell functions.}

Supplemetary Fig. 1
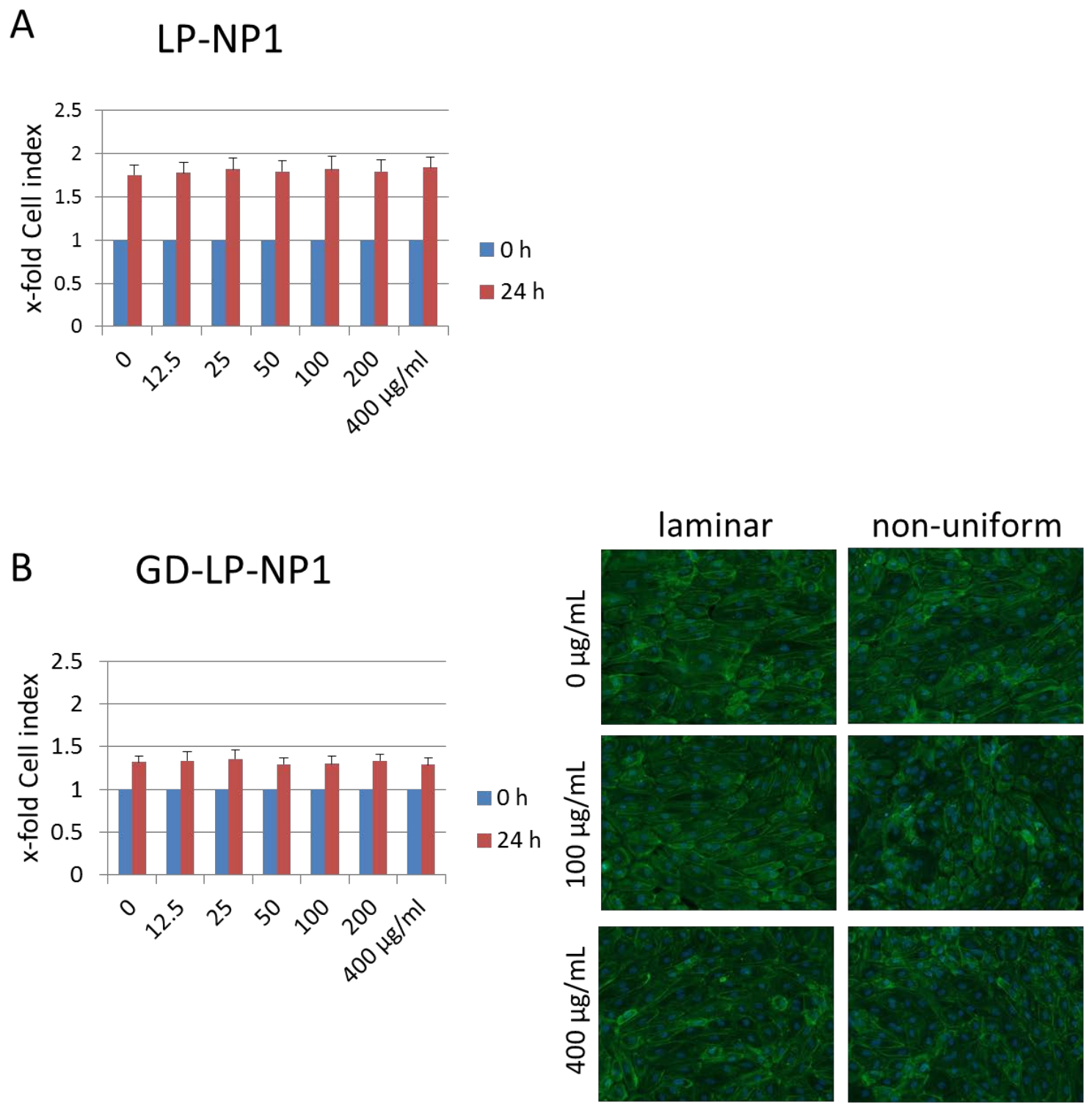

Suppl. Figure 1: Viability of endothelial cells upon treatment with LP-NP1. HUVECs were treated with (A) LP-NP1 and (B) GD-LP-NP1 for 24h. Data are expressed as mean \pm SEM of $n=3$ experiments and hexaplicate samples. Left panel: Real-time cell analysis. Cell index is displayed as $\mathrm{x}$-fold of untreated controls. Right panel: HUVECs were grown in bifurcating slides until confluence and perfused for $18 \mathrm{~h}$ with medium containing nanoparticles. Fluorescent images of representative laminar and non-uniform regions at 20x objective magnification are shown. The F-actin was visualised with cytoskeleton was stained with Alexa 488-conjugated phalloidin Alexa 488 (green) and nucleus was stained with Hoechst 33342 (blue). 


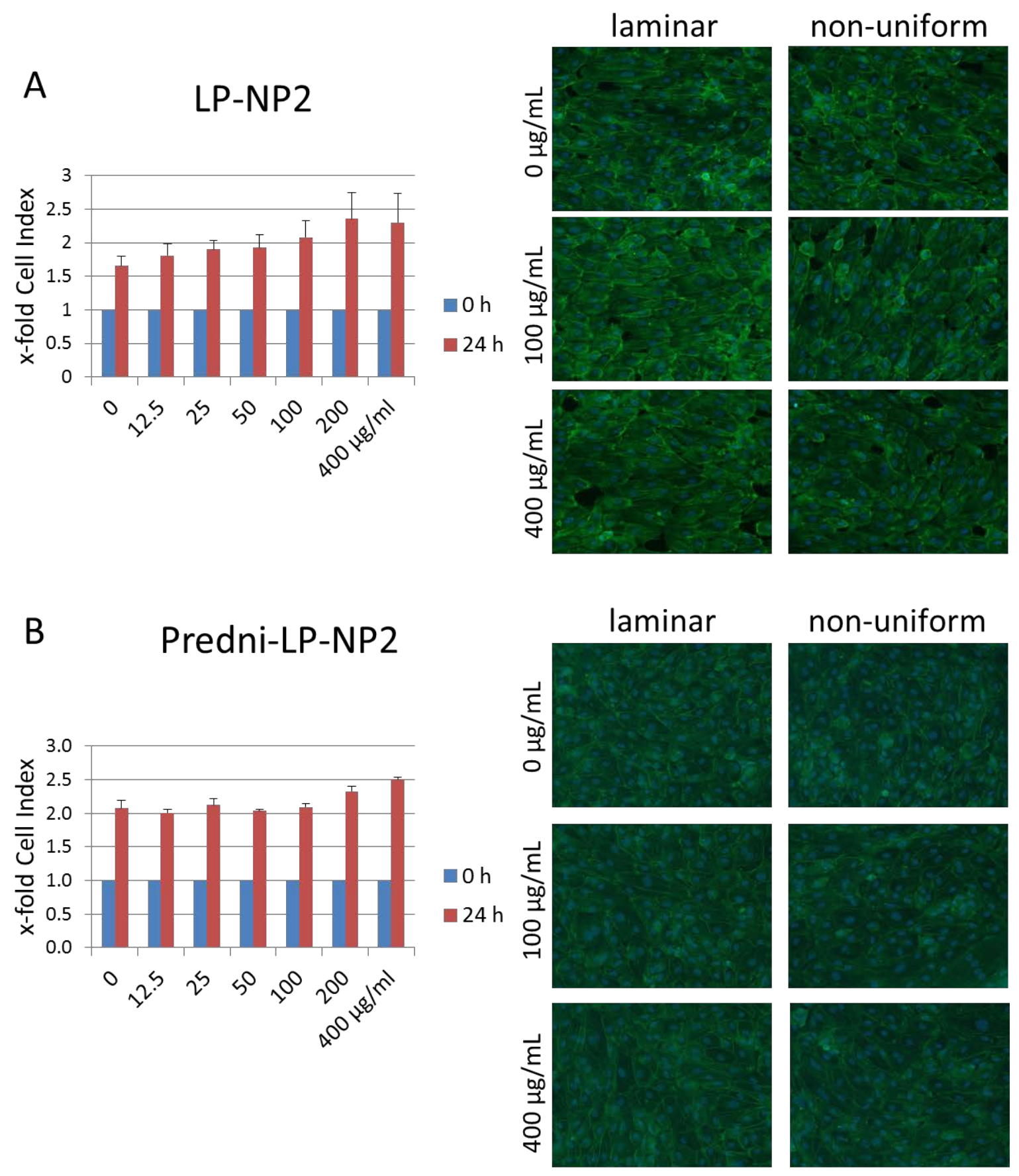

Suppl. Figure 2: Viability of endothelial cells upon treatment with LP-NP2. HUVECs were treated with (A) LP-NP2 and (B) Predni-LP-NP2 for $24 \mathrm{~h}$. Data are expressed as mean \pm SEM of $n=3$ experiments and hexaplicate samples. Left panel: Real-time cell analysis. Cell index is displayed as $\mathrm{x}$-fold of untreated controls. Right panel: HUVECs were grown in bifurcating slides until confluence and perfused for $18 \mathrm{~h}$ with medium containing nanoparticles. Fluorescent images of representative laminar and non-uniform regions at 20x objective magnification are shown. The F-actin was visualised with cytoskeleton was stained with Alexa 488-conjugated phalloidin Alexa 488 (green) and nucleus was stained with Hoechst 33342 (blue). 

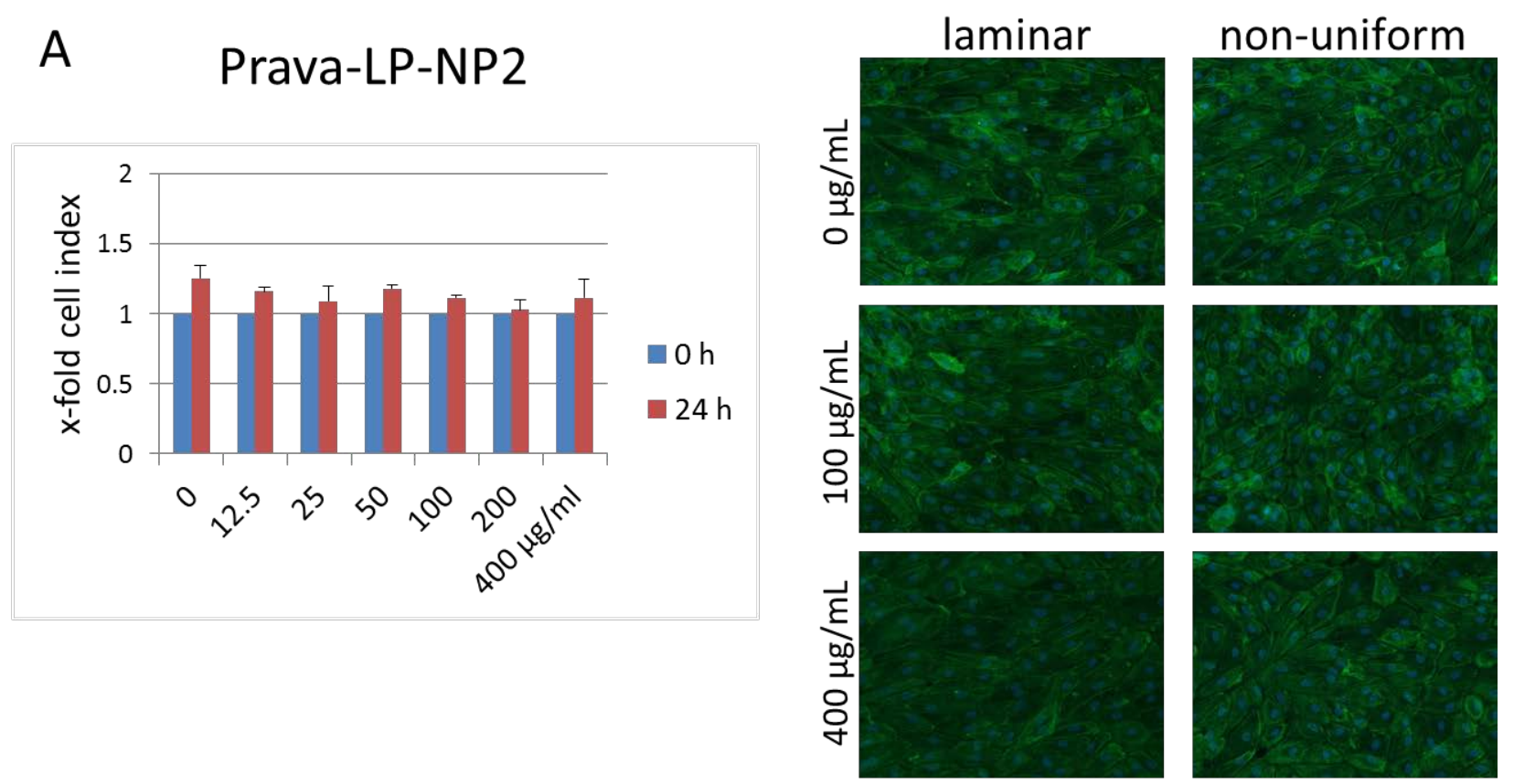

B

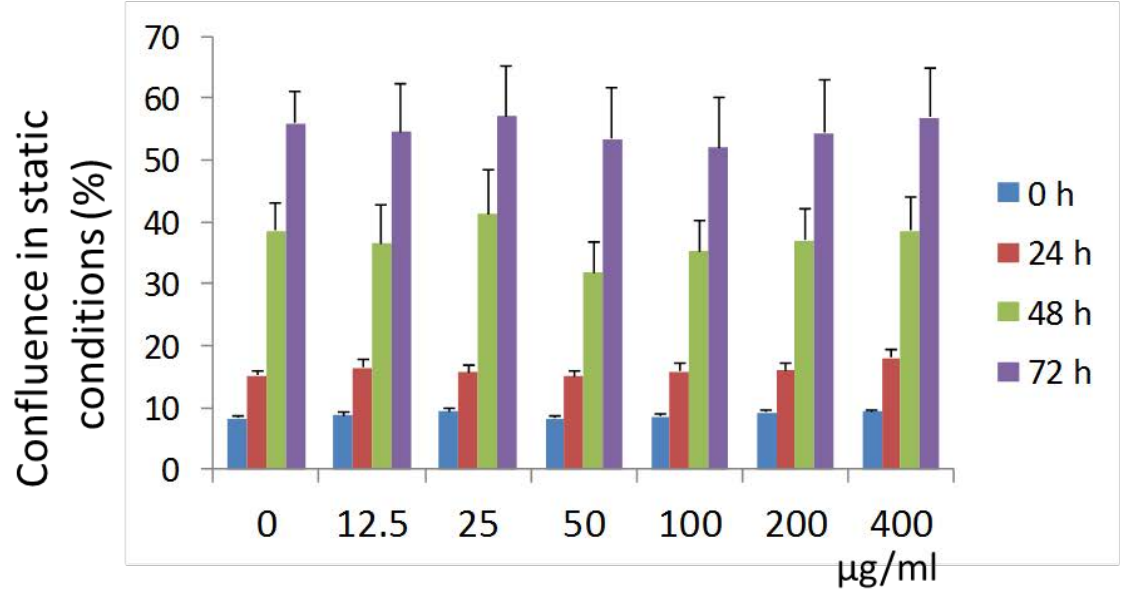

Suppl. Figure 3: Viability of endothelial cells upon treatment with Prava-LP-NP2. HUVECs were treated with (A) LP-NP2 $24 \mathrm{~h}$. Data are expressed as mean \pm SEM of $n=3$ experiments and hexaplicate samples. Left panel: Real-time cell analysis. Cell index is displayed as $\mathrm{x}$-fold of untreated controls. Right panel: HUVECs were grown in bifurcating slides until confluence and perfused for $18 \mathrm{~h}$ with medium containing nanoparticles. Fluorescent images of representative laminar and non-uniform regions at 20x objective magnification are shown. The F-actin was visualised with cytoskeleton was stained with Alexa 488conjugated phalloidin Alexa 488 (green) and nucleus was stained with Hoechst 33342 (blue). (B) HUVEC confluence upon long-term incubation with Prava-LP-NP2. Growth and morphology of cells was monitored for $72 \mathrm{~h}$ using live-cell imaging.

Note that the growth of cells monitored with real-time cell analyzed was very slow, even in control (untreated cells) during the first $24 \mathrm{~h}$, which did not allow a clear estimation of particle effect. Longerterm analysis and complementary methods (live cell imaging) was necessary to confirm that these particles did not exert any toxic effect on HUVECs up to $400 \mu \mathrm{g} / \mathrm{mL}$. 

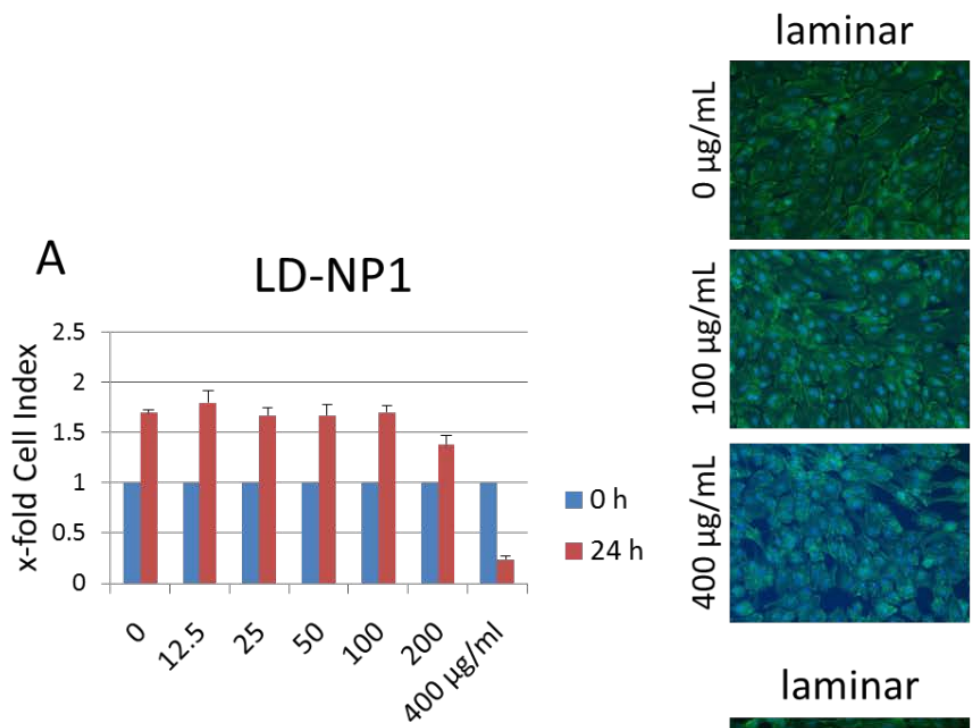

non-uniform

B
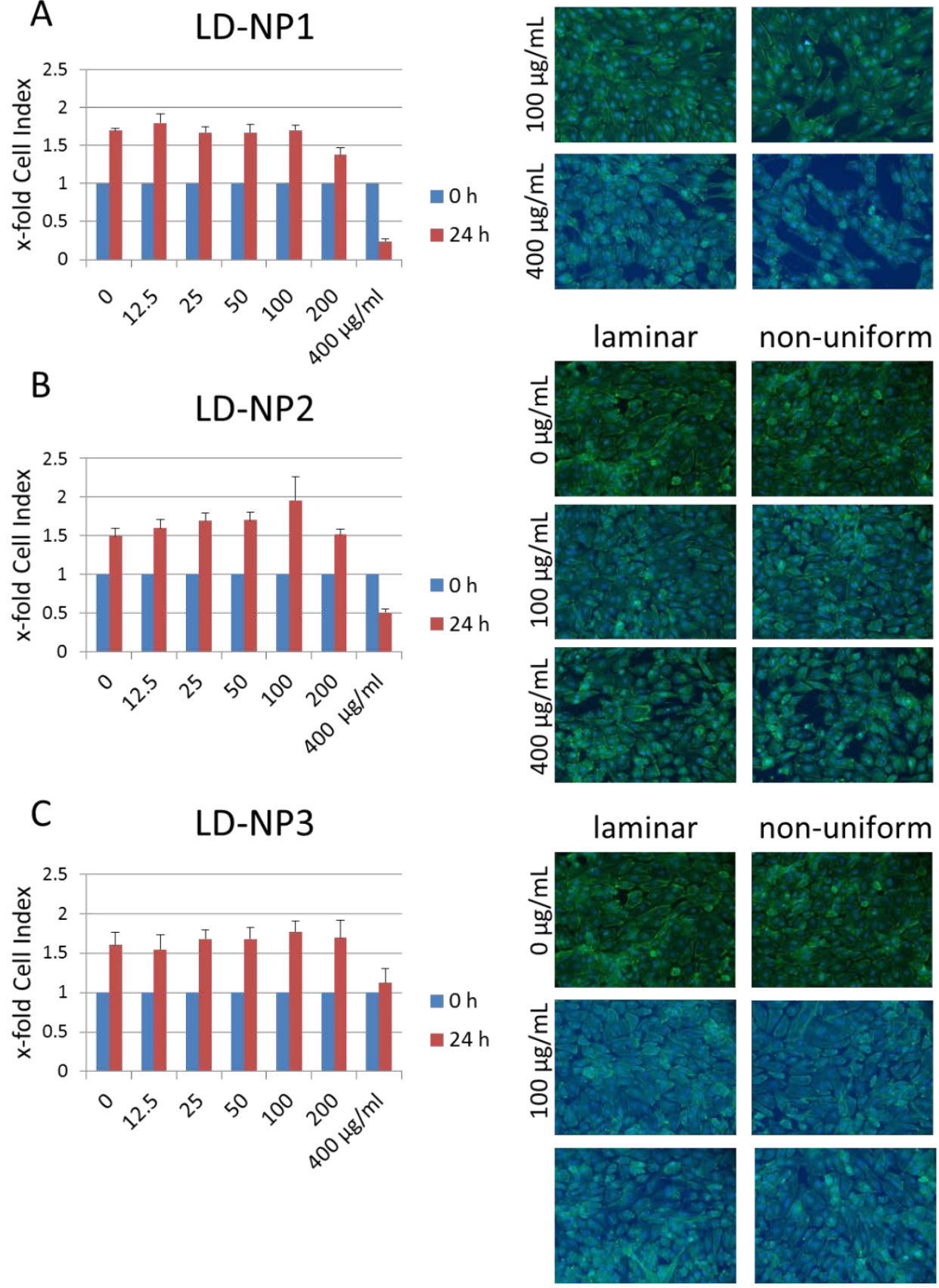

Suppl. Figure 4: Viability of endothelial cells upon treatment with LD-NPs. HUVECs were treated with (A) LD-NP1, (B) LD-NP2, or (C) LD-NP3 for $24 \mathrm{~h}$. Data are expressed as mean \pm SEM of $n=3$ experiments and hexaplicate samples. Left panel: Real-time cell analysis. Cell index is displayed as $\mathrm{x}$-fold of untreated controls. Right panel: HUVECs were grown in bifurcating slides until confluence and perfused for $18 \mathrm{~h}$ with medium containing nanoparticles. Fluorescent images of representative laminar and non-uniform regions at 20x objective magnification are shown. The F-actin was visualised with cytoskeleton was stained with Alexa 488-conjugated phalloidin Alexa 488 (green) and nucleus was stained with Hoechst 33342 (blue). 


\section{A $\quad$ FC-PM-NP1}

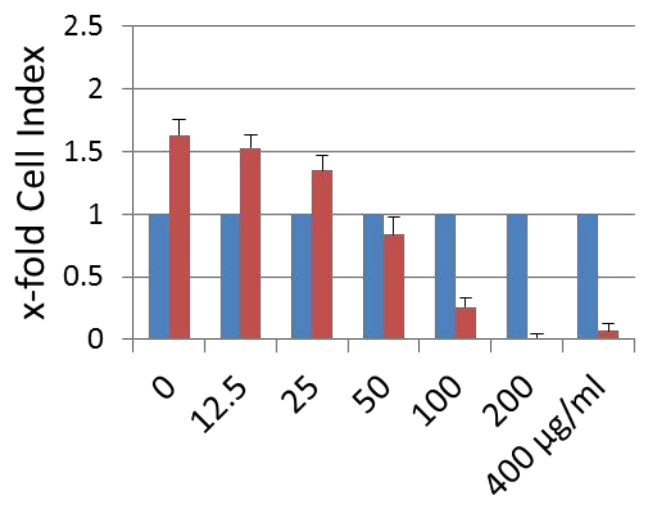

B

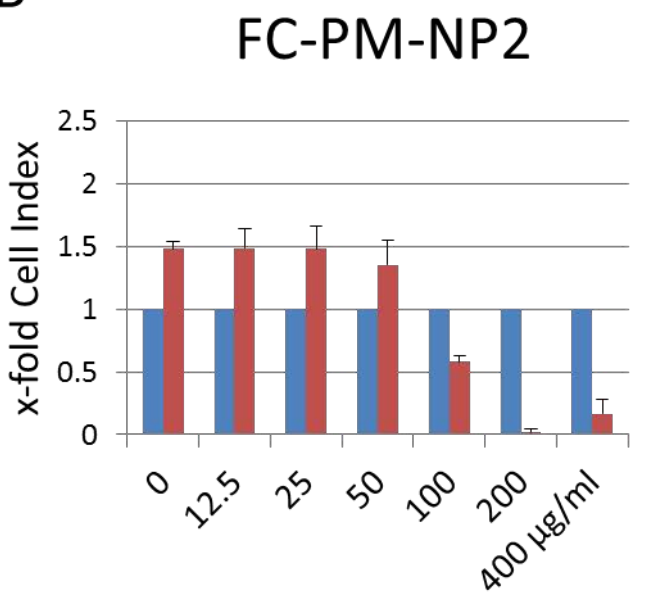

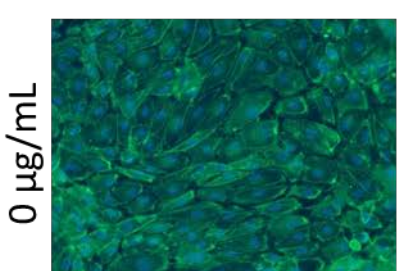
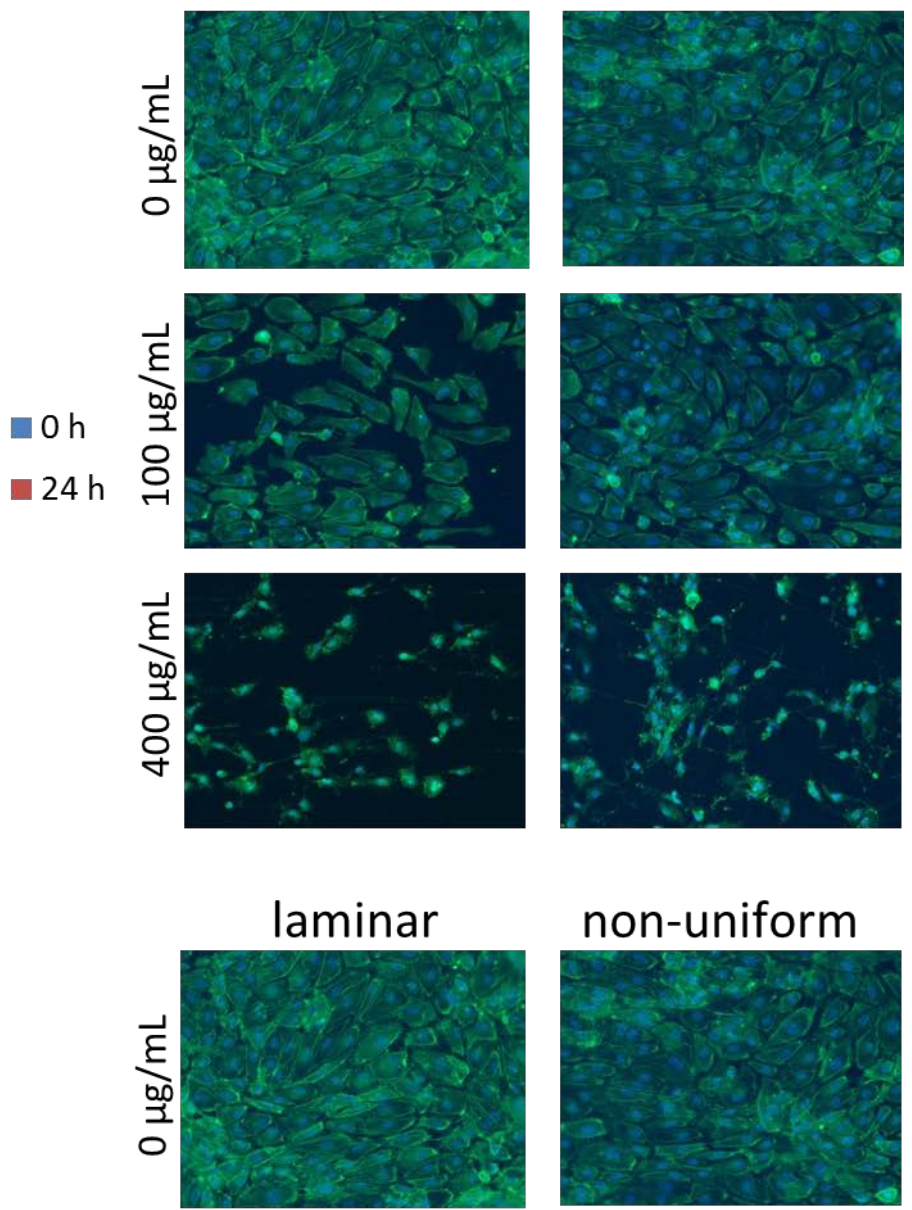

\section{non-uniform}
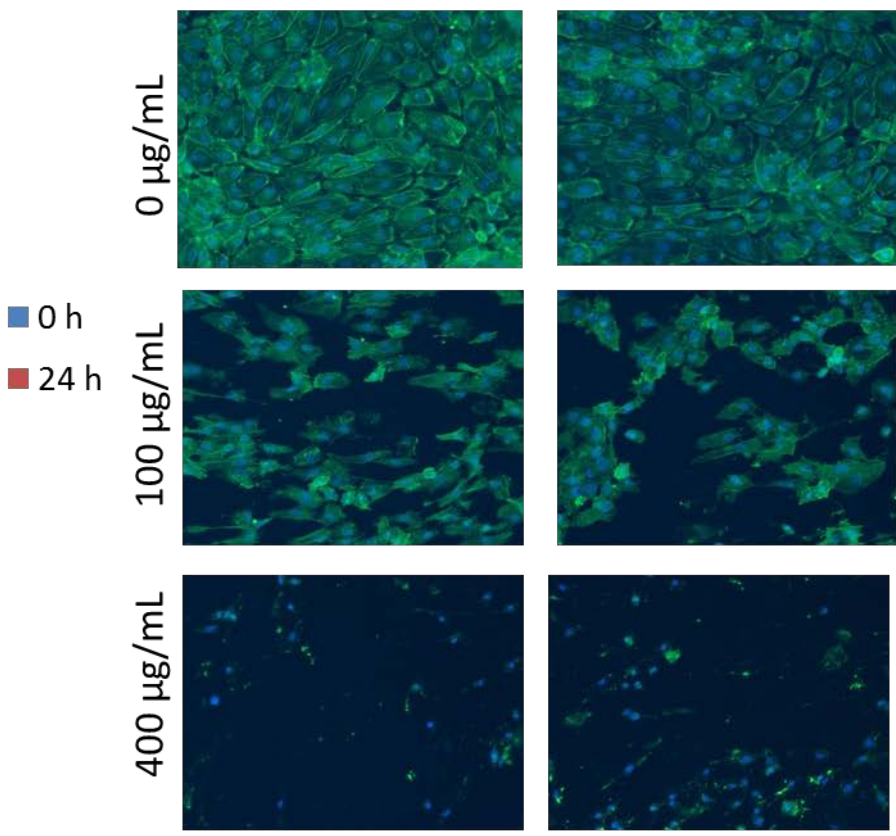

Suppl. Figure 5: Viability of endothelial cells upon treatment with FC-PM-NPs. HUVECs were treated with (A) FC-PM-NP1 and (B) FC-PM-NP2 for $24 \mathrm{~h}$. Data are expressed as mean \pm SEM of $n=3$ experiments and hexaplicate samples. Left panel: Real-time cell analysis. Cell index is displayed as $x$-fold of untreated controls. Right panel: HUVECs were grown in bifurcating slides until confluence and perfused for $18 \mathrm{~h}$ with medium containing nanoparticles. Fluorescent images of representative laminar and non-uniform regions at 20x objective magnification are shown. The F-actin was visualised with cytoskeleton was stained with Alexa 488-conjugated phalloidin Alexa 488 (green) and nucleus was stained with Hoechst 33342 (blue). 
A
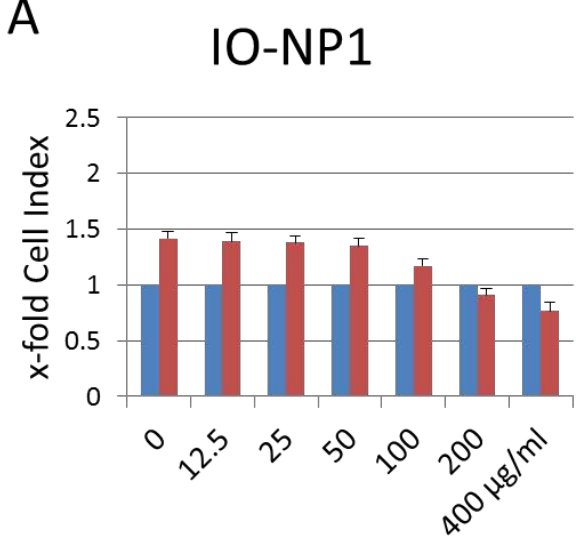

B

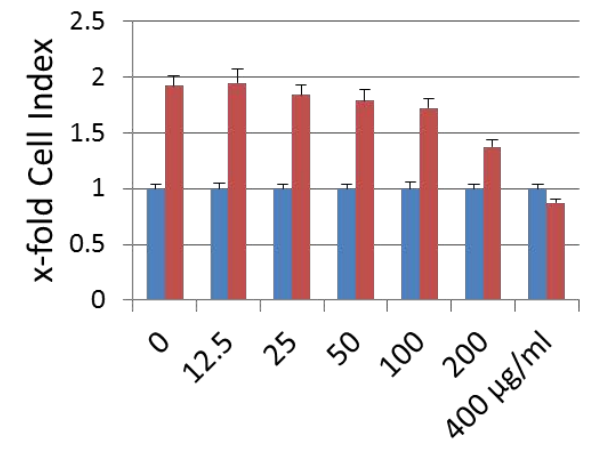

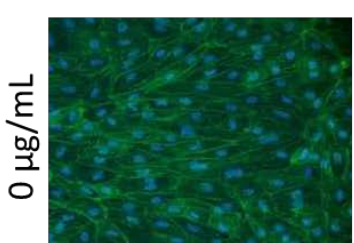
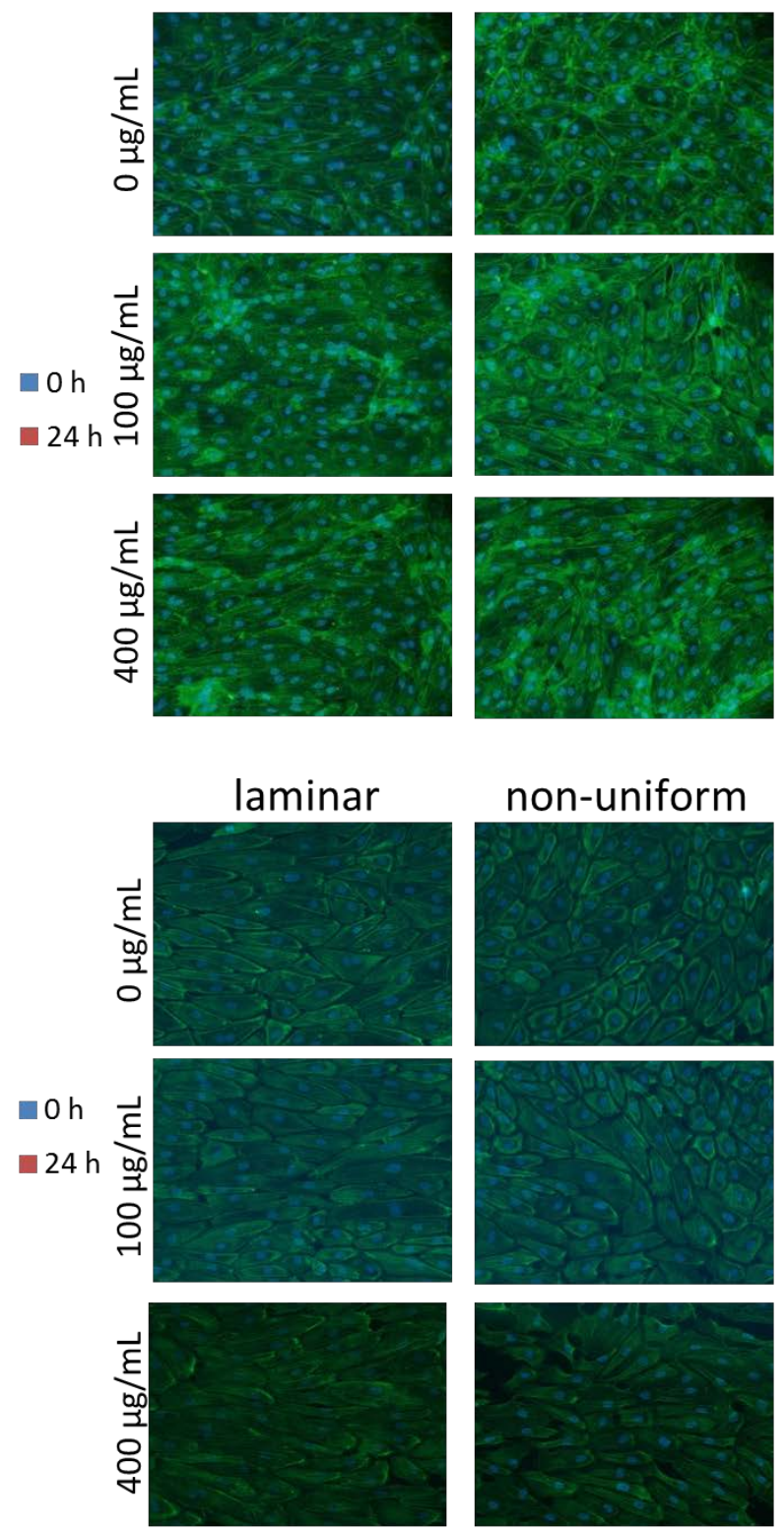

non-uniform
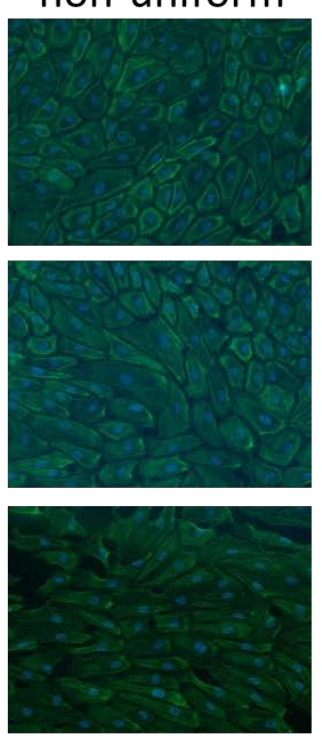

Suppl. Figure 6: Viability of endothelial cells upon treatment with IO-NPs. HUVECs were treated with (A) IO-NP1 and (B) IO-NP2 for $24 \mathrm{~h}$. Data are expressed as mean \pm SEM of $n=3$ experiments and hexaplicate samples. Left panel: Real-time cell analysis. Cell index is displayed as $x$-fold of untreated controls. Right panel: HUVECs were grown in bifurcating slides until confluence and perfused for $18 \mathrm{~h}$ with medium containing nanoparticles. Fluorescent images of representative laminar and non-uniform regions at 20x objective magnification are shown. The F-actin was visualised with cytoskeleton was stained with Alexa 488-conjugated phalloidin Alexa 488 (green) and nucleus was stained with Hoechst 33342 (blue). 
A

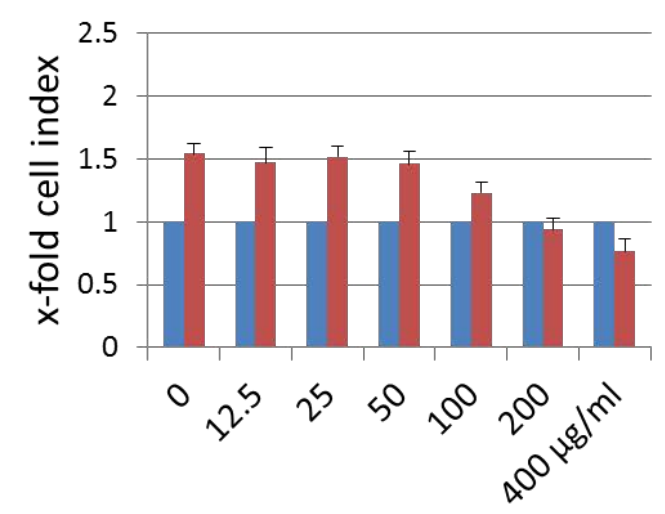

B

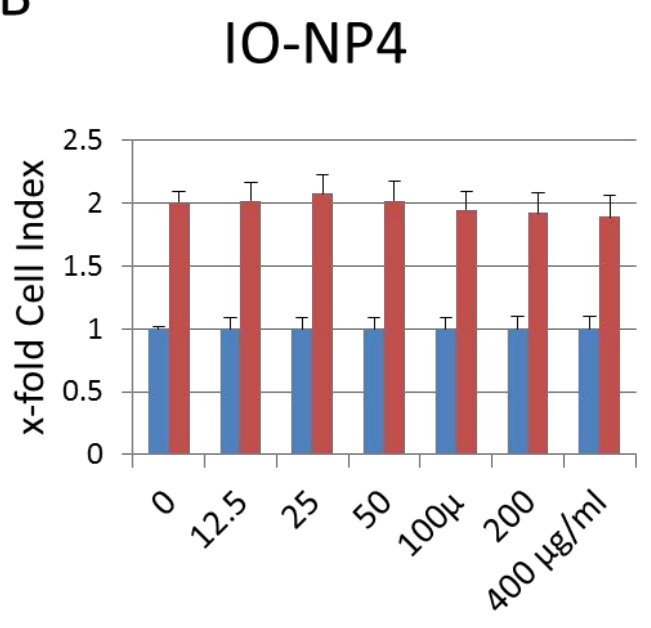

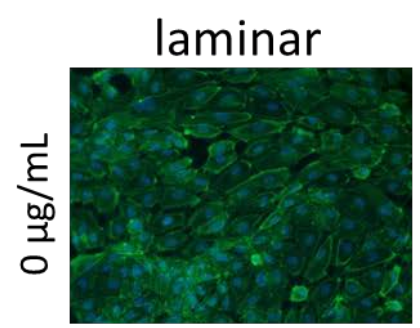

non-uniform
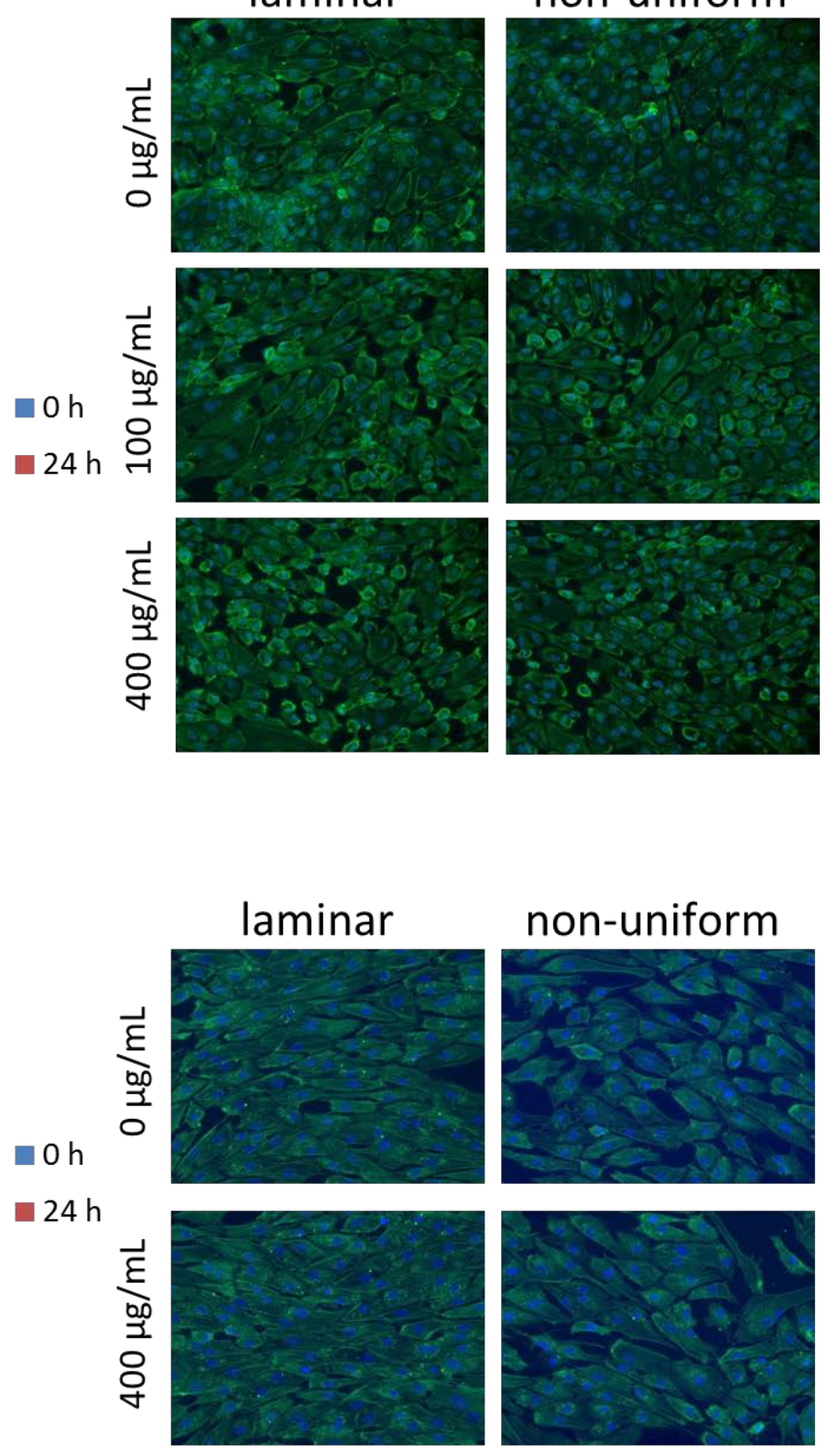
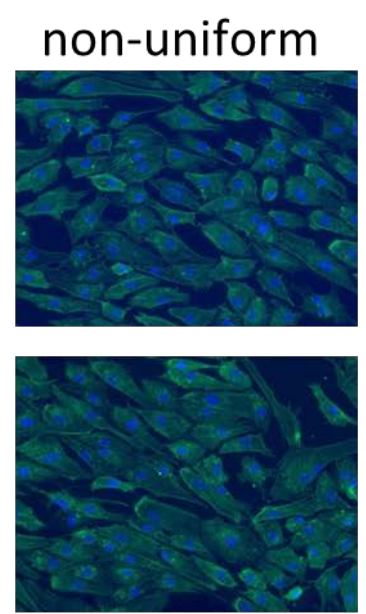

Suppl. Figure 7: Viability of endothelial cells upon treatment with IO-NPs. HUVECs were treated with (A) IO-NP3 and (B) IO-NP4 for $24 \mathrm{~h}$. Data are expressed as mean \pm SEM of $n=3$ experiments and hexaplicate samples. Left panel: Real-time cell analysis. Cell index is displayed as $x$-fold of untreated controls. Right panel: HUVECs were grown in bifurcating slides until confluence and perfused for $18 \mathrm{~h}$ with medium containing nanoparticles. Fluorescent images of representative laminar and non-uniform regions at 20x objective magnification are shown. The F-actin was visualised with cytoskeleton was stained with Alexa 488-conjugated phalloidin Alexa 488 (green) and nucleus was stained with Hoechst 33342 (blue). 
A

Control, non-uniform shear stress region

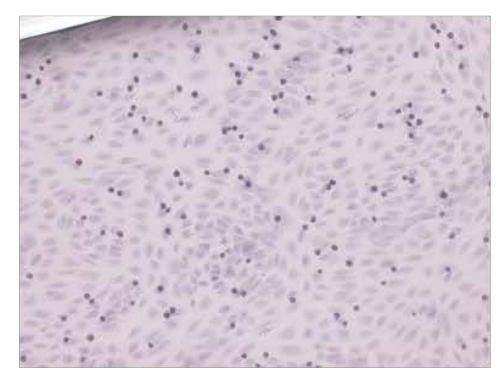

B

Control, non-uniform shear stress region

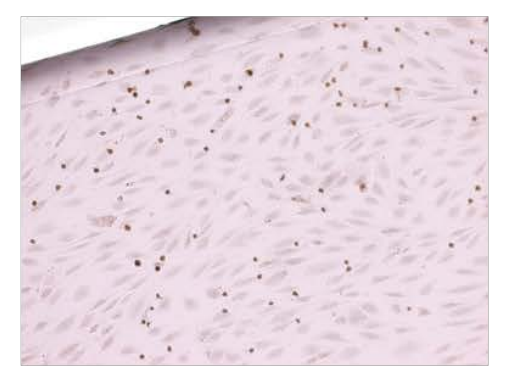

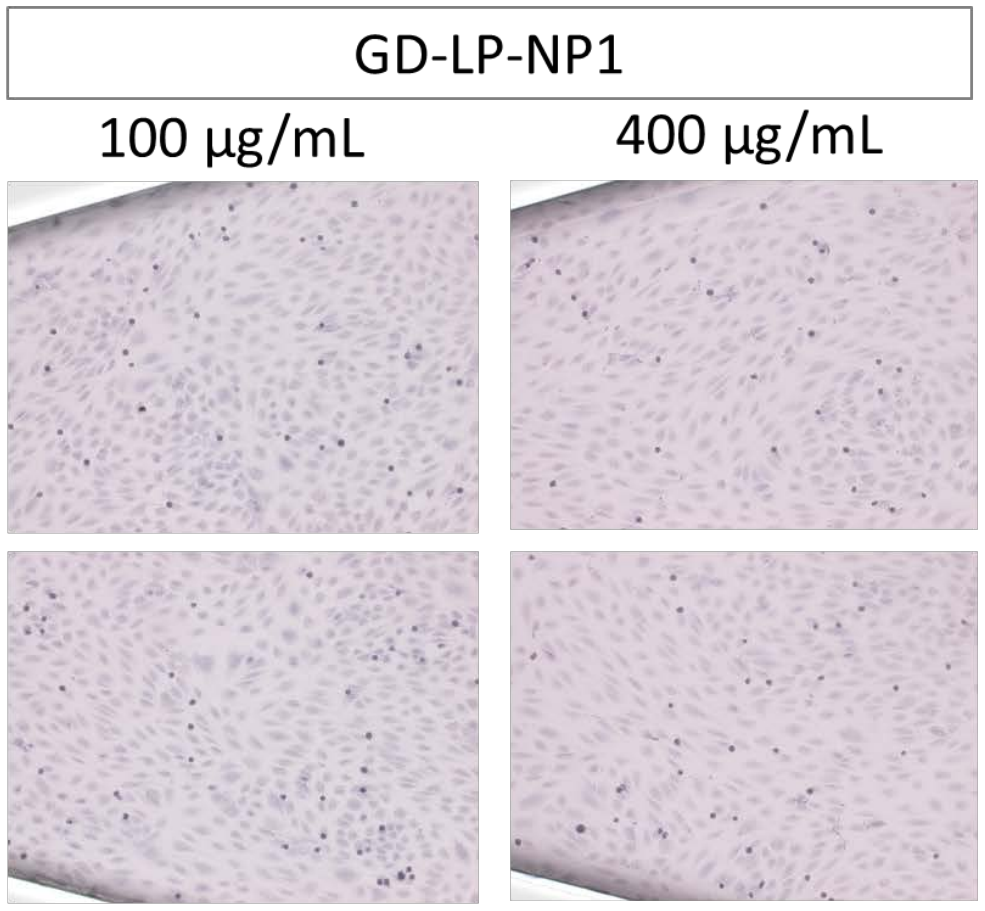
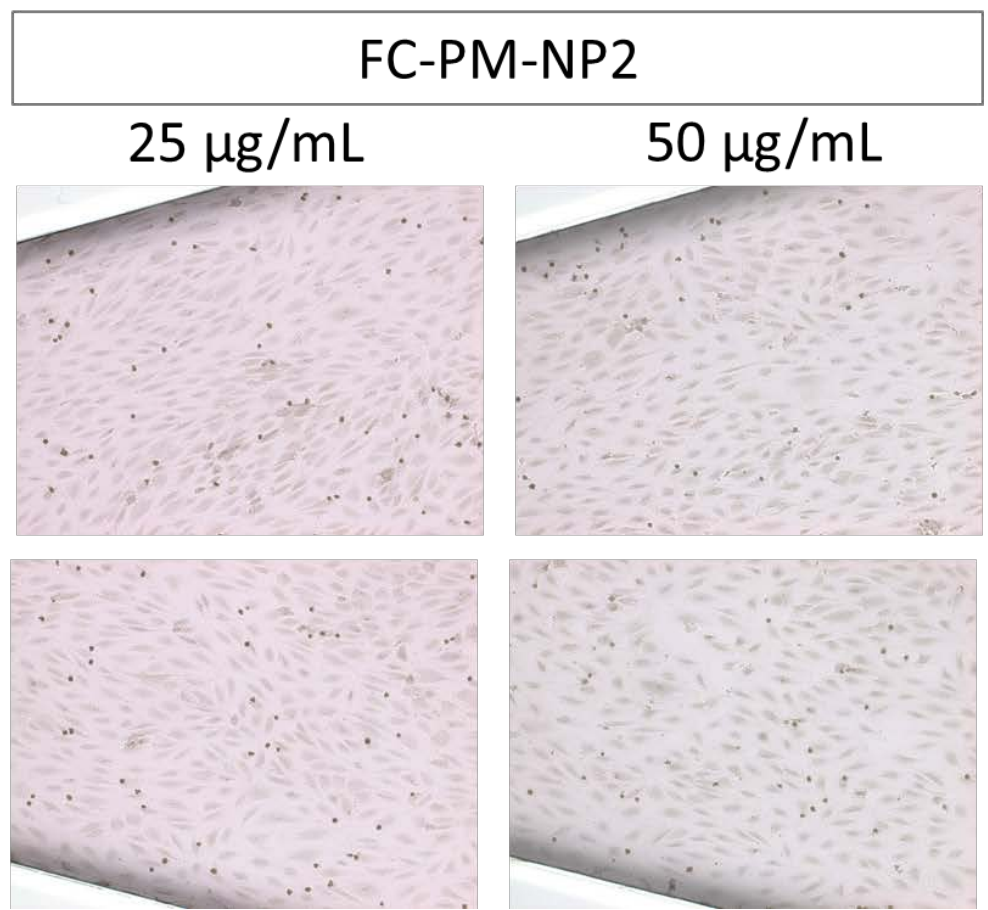

Suppl. Figure 8: Example images showing the numbers of THP-1 monocytic cells adhering to endothelial cells upon treatment with IO-NPs. HUVECs were grown in bifurcating slides until confluence and perfused for $18 \mathrm{~h}$ with medium containing (A) GD-LP-NP1 or (B) FC-PM-NP2 for 18 h. Subsequently, cells were stimulated with TNF $\alpha$ for $2 \mathrm{~h}$, followed by dynamic adhesion assay under flow conditions for 1h. Representative images of non-uniform shear stress regions, stained with hematoxylin-eosin, are shown. 
Supplementary Fig. 9.

\section{LD-NP1}

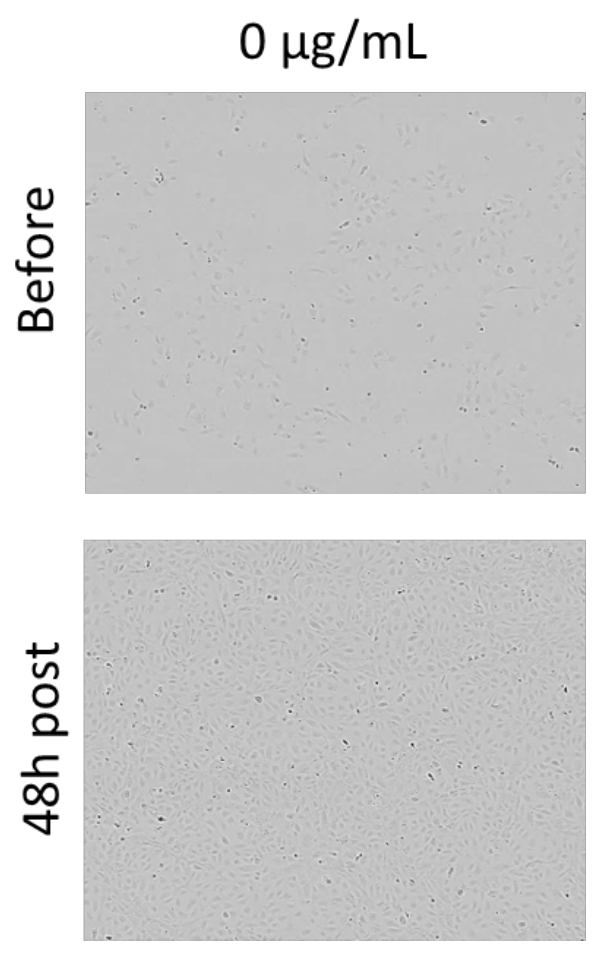

$50 \mu \mathrm{g} / \mathrm{mL}$
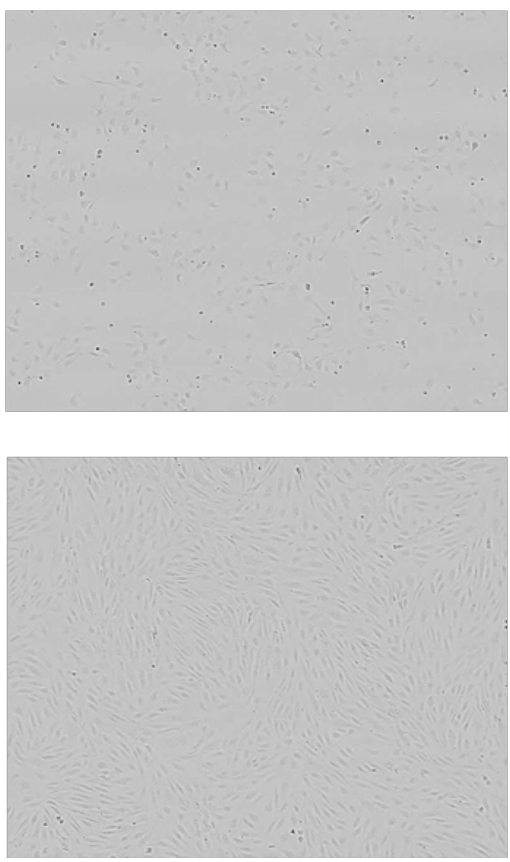

$100 \mu \mathrm{g} / \mathrm{mL}$
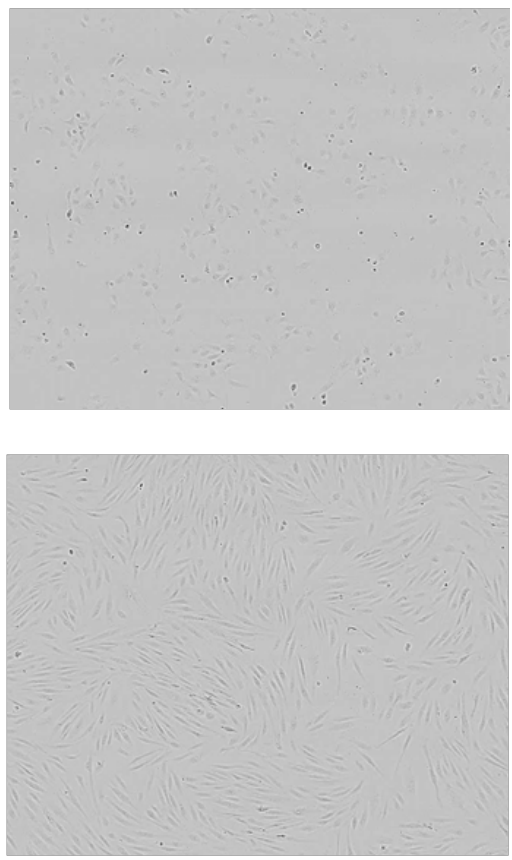

Suppl. Figure 9: Morphology of endothelial cells upon treatment with LD-NP1. HUVECs were treated with LD-NP1 $48 \mathrm{~h}$. Growth and morphology of cells was monitored using live-cell imaging. Note the pronounced cell elongation observable at $100 \mu \mathrm{g} / \mathrm{mL}$ LD-NP1. 


\section{FC-PM-NP1}

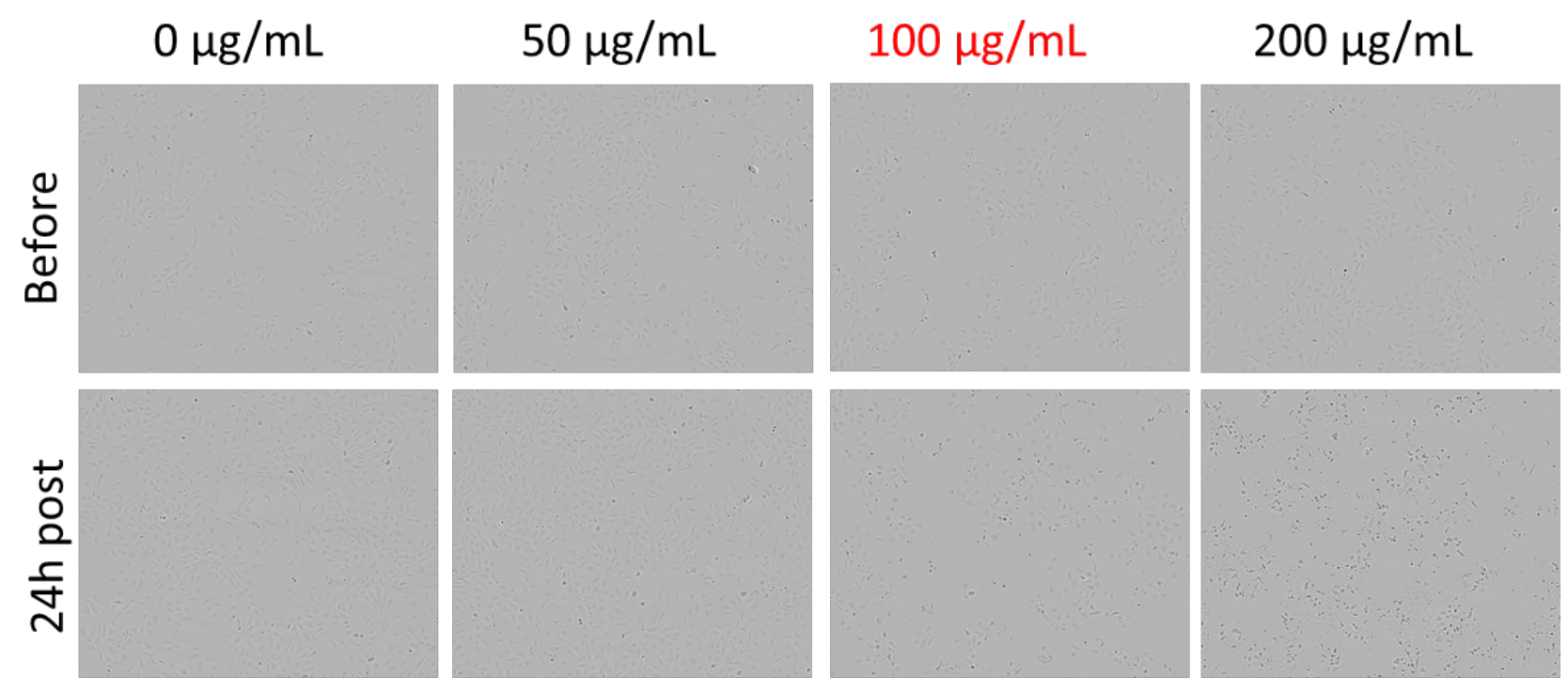

\section{FC-PM-NP2}
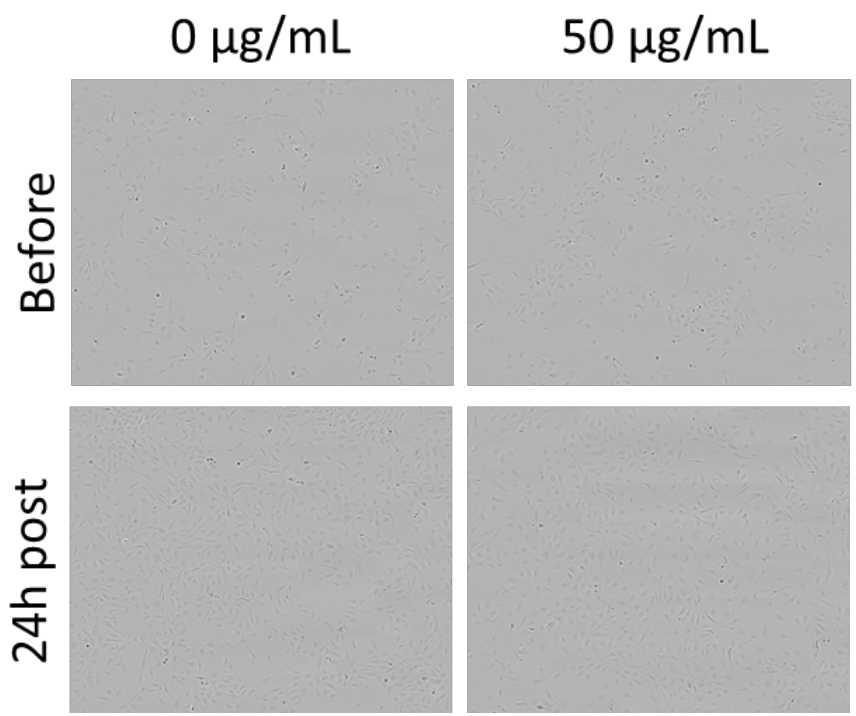

$100 \mu \mathrm{g} / \mathrm{mL}$

$200 \mu \mathrm{g} / \mathrm{mL}$
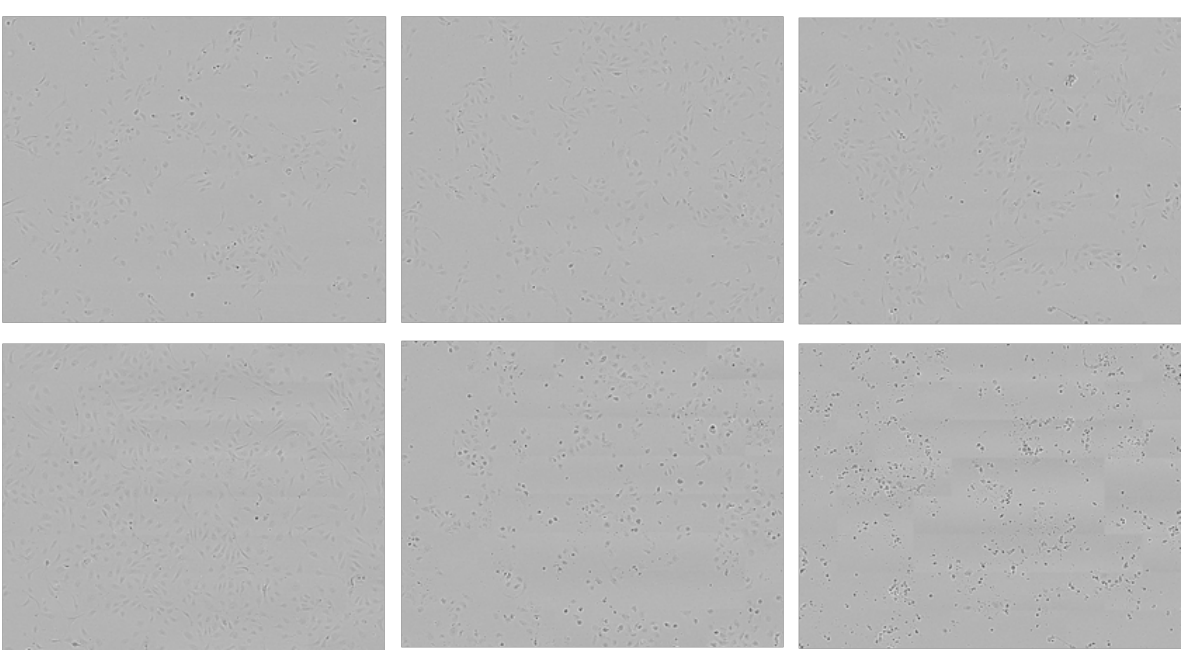

Suppl. Figure 10: Morphology of endothelial cells upon treatment with FC-PM-NPs. HUVECs were treated with FC-PM-NPs $24 \mathrm{~h}$. Growth and morphology of cells was monitored using live-cell imaging. Both types of particles were well tolerated at $50 \mu \mathrm{g} / \mathrm{mL}$, but induced toxicity at $100 \mu \mathrm{g} / \mathrm{mL}$. 


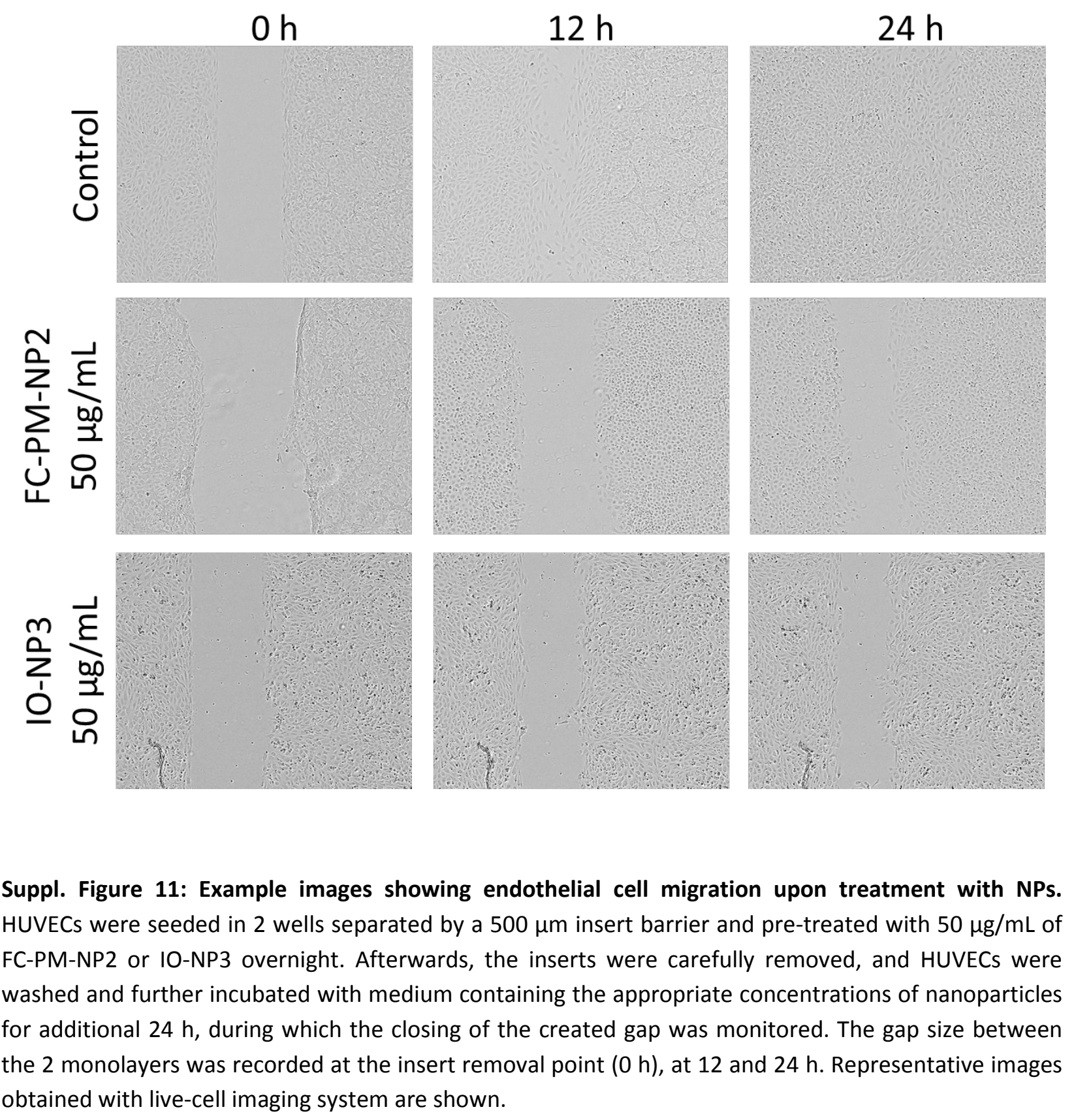

